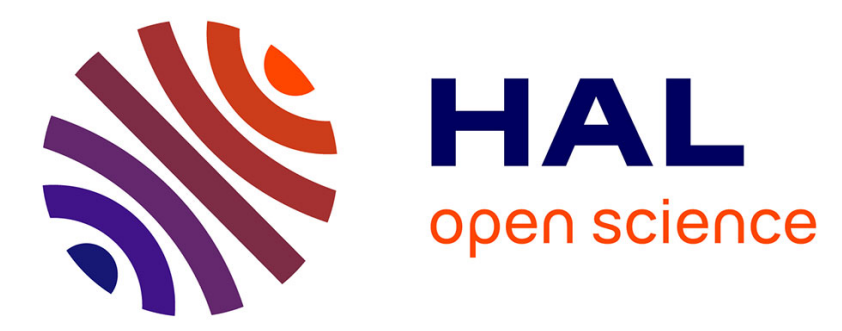

\title{
Comprehensive characterization of sooting butane jet flames, Part 2: Temperature and soot particle size
}

\author{
I.A. Mulla, J. Yon, D. Honoré, C. Lacour, A. Cessou, B. Lecordier
}

\section{To cite this version:}

I.A. Mulla, J. Yon, D. Honoré, C. Lacour, A. Cessou, et al.. Comprehensive characterization of sooting butane jet flames, Part 2: Temperature and soot particle size. Combustion and Flame, In press, pp.111596. 10.1016/j.combustflame.2021.111596 . hal-03351026

HAL Id: hal-03351026

https://hal-normandie-univ.archives-ouvertes.fr/hal-03351026

Submitted on 18 Oct 2021

HAL is a multi-disciplinary open access archive for the deposit and dissemination of scientific research documents, whether they are published or not. The documents may come from teaching and research institutions in France or abroad, or from public or private research centers.
L'archive ouverte pluridisciplinaire $\mathbf{H A L}$, est destinée au dépôt et à la diffusion de documents scientifiques de niveau recherche, publiés ou non, émanant des établissements d'enseignement et de recherche français ou étrangers, des laboratoires publics ou privés. 


\title{
Comprehensive characterization of sooting butane jet flames, Part 2: temperature and soot particle size
}

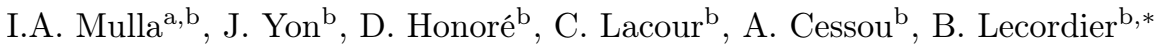 \\ ${ }^{a}$ Department of Aerospace Engineering, Indian Institute of Science, Bangalore, 560012, \\ India. \\ ${ }^{b}$ Normandie Univ., UNIROUEN, INSA Rouen, CNRS, CORIA, 76000 Rouen, France
}

\begin{abstract}
The present work investigates the effect of jet-exit Reynolds number $(R e)$ on soot particle size and flame temperature in $n$-butane jet flames. Correlation of temperature with soot volume fraction $\left(f_{v}\right)$, soot precursor (polycyclic aromatic hydrocarbons or $\mathrm{PAH})$, and reaction zone $(\mathrm{OH})$ is also examined. The investigated flames ( $R e=5000$ to 21500$)$ are identical as of the companion work (Part 1). The temperature was measured in a low-sooting region using a fine-wire thermocouple. The soot particle size distribution was obtained using a scanning mobility particle sizer (SMPS). Temporal evolution (with $0.1 \mathrm{~s}$ resolution) of $f_{v}$ in the extracted aerosol sample was monitored with a Pegasor particle sensor (PPS). $f_{v}$ from LII and PPS are compared, and the reasons for differences are discussed in detail. The radial location of peak temperature is biased towards the fuel-rich side. At Re 5000, peak-PAH occurs at $650 \mathrm{~K}$, whereas in lifted turbulent flame (Re 21500), peak-PAH shifts to $940 \mathrm{~K}$. PAH formation temperature is influenced by air/fuel mixing. Despite the variation of turbulence level $(R e=5000-21500)$, peak- $f_{v}$ in the soot inception region occurs at a nearly identical temperature of $1400 K$. Peak- $f_{v}$ shifts towards lower temperature with increasing height, likely due to oxidation by diffused $\mathrm{OH}$. The soot mode diameter $\left(D_{m}\right)$ was measured along the axis. $D_{m}$ increases with height and reaches a maximum near peak- $f_{v}$ region. $D_{m}$ at moderate $R e$
\end{abstract}

\footnotetext{
* Corresponding author:

Email address: bertrand.lecordier@coria.fr (B. Lecordier)
} 
$(5000-21500)$, varies between $12-28 \mathrm{~nm}$ along the flame axis. At high $R e$ (21500), $D_{m}$ range decreases to $12-24 \mathrm{~nm}$. The decrease in peak- $D_{m}$ with $R e$ is likely due to reduced residence time and enhanced reactant mixing. The comprehensive database containing a wide range of parameters from the present and companion (Part 1) papers will aid in the development and validation of turbulence and soot chemistry models, especially for fuels of practical relevance. Keywords: turbulent sooting flames, butane, soot, SMPS, soot particle size

\section{Introduction}

This is the second paper of a two-part series on the characterization of sooting $n$-butane jet flames. In turbulent flows, to predict soot formation, turbulence and soot chemistry processes are modeled. These models are generally assessed

5 against an experimental database. Therefore, the database-oriented works have been reported in turbulent sooting flames, both in jet [1-3] and swirl stabilized [4-7] flame configurations. These databases proved to be valuable in the assessment of numerical models in turbulent jet [3, 8] and swirl [9-12] flames. These past studies primarily focused on ethylene fuel owing to high soot yield and well-established chemical kinetics. However, investigations of soot formation in larger alkanes such as $n$-butane are necessary to develop soot chemistry models for fuels of practical relevance. Thermochemical and combustion characteristics of $n$-butane are similar to the fuels of practical interest $[13,14]$. $n$-butane is the smallest paraffin that mimics oxidation of larger paraffins contained in gasoline [15]. Therefore, to validate soot models intended for practical fuels, there is a need for a benchmark database with surrogate fuels besides ethylene. For these reasons, we comprehensively characterized sooting $n$-butane jet flames using a range of experimental methods. The companion paper [16], focuses on the effect of jet-exit Reynolds number $(R e)$ on soot concentration, soot precursors, and reaction zone. Laser-induced fluorescence (LIF) and laser-induced incandescence techniques (LII) were used to obtain the data non-intrusively. The present paper (Part 2) investigates the effect of $R e$ on soot size and soot-temperature 
correlations in identical $n$-butane jet flames [16], including the turbulent flow condition.

In Part 1 [16], previous studies in turbulent sooting jet flames are reviewed in detail. Therefore in this part, the literature focused on temperature and soot size are discussed. For a given fuel, the soot formation process depends on the following local conditions, namely mixing field, velocity field, residence time, and temperature. In turbulent flame, many of these local properties fluctuate simultaneously, which poses difficulty in assessing the impact of an individual parameter on soot formation. The temperature is one of the most important quantities which governs soot formation and oxidation. The investigation by Coppalle and Joyeux [17] provided correlations between temperature and soot volume fraction $\left(f_{v}\right)$ in ethylene jet flames at different Re. The authors [17] 35 used an optical probe, which provided extinction-based $f_{v}$, while the temperature was deduced through two-color pyrometry. Such optical probe-based $f_{v}$ and temperature were also reported by Shaddix et al. [18]. Although the technique provides simultaneous measurements, the probe perturbation and low spatial resolution are the limitations. Chan et al. [19] reported temperature and soot concentration in laminar flames using two-line LIF thermometry and LII. The flame wrinkling was demonstrated [19] to have an impact on soot-temperature correlations. A similar measurement technique was applied to turbulent flames [20], where a strong correlation between soot presence and a certain temperature range was noted. Kohler et al. [2] measured temperature in turbulent ethylene 45 jet flame using coherent anti-stokes Raman scattering. Gu et al. [21] investigated a similar flame by simultaneously measuring temperature, $f_{v}$, and soot size. Joint statistics between various parameters, including $f_{v}$ and temperature, were reported. A similar measurement approach was employed by Kruse et al. [22] to investigate soot oxidation in turbulent toluene flame. Park et al. [23] so compared the temperature deduced from Krypton LIF with the fine-wire thermocouple measurements. An excellent agreement between the thermocoupleand LIF-based measurements was demonstrated. Park et al. [24] used Krypton LIF to investigate $f_{v}$ and temperature correlations in the soot inception region of 
nitrogen-diluted ethylene flame. These investigations [19-24] suggest a preferred temperature range (typically, $1200-1600 K$ ) where $f_{v}$ peaks. Besides ethylene flame, it is of interest to assess such soot-temperature correlations in $n$-butane flames since its oxidation chemistry is similar to that of larger paraffins present in practical fuels. In the present work, the temperature was measured in lowsooting regions using a fine-wire thermocouple. The mean temperature profiles are compared with the time-averaged $f_{v}$ from LII to investigate correlations.

Soot particle size can also be used to validate simulation models, as in Ref. [12]. The soot particle diameter can be measured either in a traditional ex-situ manner or using non-intrusive optical techniques. Time-resolved LII (TR-LII) can provide the primary diameter $\left(d_{p}\right)$ of soot aggregates but not the aggregate 65 size. To obtain the soot aggregate size, TR-LII and elastic scattering techniques were combined [25] to obtain the radius of gyration $\left(R_{g y}\right)$ and the number of primary particles per aggregate $\left(N_{p}\right)$. Such complete description $\left(f_{v}, d_{p}, R_{g y}\right.$ and $N_{p}$ ) of soot concentration, soot size, and morphology has been reported in laminar ethylene flame [25]. In turbulent ethylene flame, Gu et al. [26] reported the axial variation of soot primary diameter $\left(d_{p}\right)$, based on TR-LII. The $d_{p}$ measurements were also reported in toluene flame [22].

A scanning mobility particle sizer (SMPS) is an ex-situ technique which can provide the soot particle size distribution (PSD) and concentration. Note that SMPS measures the size of a soot aggregate (mobility diameter, $d_{m}$ ). Thus, 75 the SMPS-derived aggregate size $\left(d_{m}\right)$ will differ from LII-deduced $d_{p}$. In lowsooting $n$-butane laminar flames [27], a good agreement between LII- and SMPSbased soot sizes is demonstrated. Agreement between mode $d_{m}$ and $d_{p}$ in [27] suggests no soot aggregation in a nascent soot particle. Several studies have reported soot PSD in laminar ethylene flame using SMPS. Zhao et al. [28] so observed a unimodal PSD in the inception region, which subsequently developed a bimodality with increasing height above the burner. The bimodality was solely associated with primary particles [29]. The work of Gu et al. [26] showed that the PSD shapes are highly sensitive to the flame temperature and equivalence ratio. Such PSD studies in $n$-butane flames are relatively few [30], even in 


\section{Experimental methods}

\subsection{Burner and Flame condition}

The measurements were performed in $n$-butane non-premixed jet flames at atmospheric pressure. The burner geometry and flame conditions are detailed in Part 1 [16]. $n$-butane was issued through a $2.4 \mathrm{~mm}$ tube in the co-flowing air. The flames were enclosed in a square duct (400 $\mathrm{mm}$ wide and $750 \mathrm{~mm}$ high) through which co-flow air was issued. The air co-flow was maintained at $5 \mathrm{~g} / \mathrm{s}$, which is high enough to ensure the over-ventilated flame condition. The flow 
rates were regulated by Coriolis-calibrated thermal mass flow controllers [16]. The uncertainty in flow rates is estimated to be within $\pm 1 \%$. Three $n$-butane flames (Re 5000, 7200, and 21500) out of the four cases investigated in [16] are considered. The Re 2100 flame was not suitable for intrusive measurements due to large soot concentration and low jet momentum, which could result in significant probe-induced perturbations.

$R e$ is defined based on the jet-exit bulk velocity and tube diameter. Generally, the turbulence level increases with $R e$ [36]. Therefore, Re has been used $[37,38]$ as a global parameter to represent the overall turbulence level. Re was varied from 2100 to 21500 by changing the fuel flow rate from 0.03 to $0.3 \mathrm{~g} / \mathrm{s}$. Consequently, $R e$ variation was accompanied by a change in residence time since the bulk velocity (flow rate) was altered. Therefore, to assess the effect of local turbulence, the velocity field needs to be measured (e.g., [39]). In the present work, the local velocity was measured only for Re 21500 in the jet-exit region. Thus, the effect of local turbulence on soot could not be assessed explicitly.

Re 5000 flame was attached to the fuel tube, while $R e 7200$ and 21500 flames were lifted with 11 and $53 \mathrm{~mm}$ lift-off heights, respectively [16]. From the modeling point of view, a database of the attached flame is preferred [1] due to difficulty in modeling lifted flames owing to the partial premixing at the flame base. In general, a pilot flame has been used [1] to avoid the lift-off at high $R e$; however, the pilot flame is argued [2] to introduce modeling complexities.

135 Another approach is to use an additive in fuel or oxidizer stream, such as $\mathrm{H}_{2}$ [40] or $\mathrm{O}_{2}$ [41] to keep the flame attached. This approach was not used in the present work since the database with pure $n$-butane was intended. Instead, we provide the precise velocity and mixing fields in a lifted part of the flame (for Re 21500) as boundary conditions.

\subsection{Laser diagnostics}

The present paper uses the soot concentration, soot-precursor (PAH), and flame location $(\mathrm{OH})$ data obtained in the companion work [16]. A brief description of the measurement methods is provided here, while detailed information 
can be found in [16]. Soot volume fraction was measured using the LII technique. Soot particles were heated by a $1064 \mathrm{~nm}$ wavelength pulse (from a $\mathrm{Nd}$ :YAG laser), and the resulting incandescence signal was acquired at $400 \mathrm{~nm}$. The average laser fluence of $0.4 \mathrm{~J} / \mathrm{cm}^{2}$ was used to ensure the plateau regime of LII. The LII signal was imaged on an intensified CCD (ICCD) camera with a prompt gating of $50 \mathrm{~ns}$ relative to the laser pulse. To obtain the soot volume fraction, the LII signal was calibrated using a laser-extinction measurement at $1064 \mathrm{~nm}$. To image $\mathrm{OH}$ and PAH distributions, the planar laser-induced fluorescence (PLIF) technique was used. The $\mathrm{OH}$ radical was excited using $283 \mathrm{~nm}$ wavelength (from a dye laser) with $0.05 \mathrm{~J} / \mathrm{cm}^{2}$ average fluence. The resulting $\mathrm{OH}$ fluorescence was imaged at $310 \mathrm{~nm}$ using an emICCD camera gated to $30 \mathrm{~ns}$ width. PAH is excited with $283 \mathrm{~nm}$ wavelength laser pulse at a reduced fluence $\left(0.02 \mathrm{~J} / \mathrm{cm}^{2}\right)$ to avoid the LII interference. The PAH-PLIF signal was acquired in a $350-400 \mathrm{~nm}$ range with an ICCD camera gated to $50 \mathrm{~ns}$ width. These excitation and detection parameters provide the LIF signal primarily from 2-4 ring PAH [42]. In all the above diagnostics, the signal was imaged at a magnification of 5.75 pixels $/ \mathrm{mm}$, which corresponds to $89 \mathrm{~mm}$ wide field-of-view (FOV). A total of 1000 to 2000 images (depending on height above the burner) were acquired at a $10 \mathrm{~Hz}$ rate. The time-averaged data sets of $f_{v}$, OH-PLIF, and PAH-PLIF from [16] are used in the present paper to investigate their correlations with temperature.

\subsection{Temperature measurements}

The gas temperature was measured using a fine-wire thermocouple. A TypeB thermocouple (Pt-30\%Rh / Pt-6\%Rh) was chosen due to its high temperature limit. Thermocouple wires of $50 \mu \mathrm{m}$ diameter were butt-welded to form a junction. The junction was exposed to the flame, while the extension wires were shielded in a twin-bore ceramic tube. The thermocouple signal was amplified and digitized at a $3 \mathrm{kHz}$ rate. The lowest measurable temperature was limited to $530 \mathrm{~K}$ due to a weaker thermocouple signal. The thermocouple was traversed through the flame using a 3 -axis motorized stage. The translation 
stage and data acquisition system were integrated to automate the measurements. Any misalignment between the thermocouple translation and flame axes was minimized through a $2 \mathrm{D}$ temperature mapping at two different heights (planes). This provided the flame axis and its orientation with reference to the thermocouple translation coordinates.

Temperature measurements are intended to be quantitative. Therefore, various uncertainty sources, namely 1) calibration error, 2) catalytic effects, 3) local flame perturbations, and 4) radiation correction uncertainty, are assessed. The calibration accuracy was verified by measuring known temperatures (within the $570-1060 \mathrm{~K}$ range) in a portable calibration furnace (Pegasus 1200B, AOIP). The conduction heat losses through thermocouple wires can be neglected since the wire length was long $(10 \mathrm{~mm})$ relative to the diameter $(50 \mu \mathrm{m})$. In reducing atmospheres, the platinum surface can act as a catalyst that may enhance exothermic reactions. A non-catalytic coating could have been used; however, such coating deteriorates the temporal response in turbulent flames. Therefore, the uncoated bare thermocouple was used. The catalytic effects in non-premixed flames were speculated to be insignificant due to lower radical concentration [43]. This is confirmed by an excellent agreement between LIF-based temperature and thermocouple (uncoated) measurements that are reported by Park et al. [23]. Nevertheless, we assessed the catalytic effects by traversing the thermocouple from oxidizer to fuel stream and vice-a-versa. The hysteretic effects were not significant in the present flames (see Fig. S1 in Supplement).

Since the thermocouple size was small $(50 \mu \mathrm{m})$, no significant flame perturbations were noted, as evidenced from Fig. 1, where lift-off height and overall flame appearance with and without the thermocouple are identical. The measurements stations are marked on respective flame photographs in Fig. 2. The 200 Re 5000 flame is attached, while other flames are lifted. The lift-off heights for Re 7200 and 21500 measured 53 and $11 \mathrm{~mm}$, respectively, based on OH-PLIF data [16]. Since the Re 2100 flame was highly sooting, the temperature was not measured. In remaining flames, measurements were limited to low-sooting regions, where time-averaged $f_{v}$ is below 0.1 ppm (deduced from LII measure- 
205 the thermocouple junction, consequently resulting in a large uncertainty. To reduce the effect of soot deposition, the measurement duration was limited to $3 s$ at each location. In the case of soot deposition, the temperature was reported to decrease even within the first two seconds [43]. Over the present $3 \mathrm{~s}$ duration, the temperature did not decay (see Fig. S2), which suggests negligible soot deposition. Additionally, no visible deposition was noted at the end of measurements. The radiation correction is necessary since the flame temperature is anticipated to be high $\left(T_{a d}=2267 \mathrm{~K}\right)$. The correction is applied by considering a convection-radiation balance as detailed in Sec. S1.3 of the Supplement.

The detailed estimates of uncertainties owing to errors in radiation correction, positional error, and statistical uncertainty in mean temperature are provided in Sec. S1.4. The combined uncertainty in mean temperature at a peak value $(2250 \mathrm{~K})$ is estimated to be $\pm 6 \%$, while uncertainty is $\pm 4 \%$ in the temperature range of $600-1600 \mathrm{~K}$.

\subsection{Particle analyzers}

A Pegasor particle sensor (PPS) was used to measure the soot concentration, whereas the scanning mobility particle sizer (SMPS) was employed to measure the soot particle size simultaneously. Both SMPS and PPS measurements require the extraction of an aerosol sample from the flame. Figure 3 shows the orifice drilled in a probe tube of $4 \mathrm{~mm}$ inner diameter and $1 \mathrm{~mm}$ wall thickness To draw the sample, a mild vacuum was generated by a pump. The suction strength was controlled by a valve. The sample was quickly diluted with nitrogen $\left(N_{2}\right)$ that was issued through the tube at a 10 liters per minute $(l p m)$ flow soot aggregation. Apart from $N_{2}$, additional dilution (with air) was achieved using two diluter units (VKL 10, PALAS) connected in tandem. This provided an additional dilution factor of 100 . Such a heavy dilution is necessary to avoid the saturation of SMPS and PPS. 

miniCAST soot (miniCAST 5200, Jing) generator. Soot generated by miniCAST propane $(0.06 \mathrm{lpm}) /$ air $(1.5 \mathrm{lpm})$ flame was very stable and reproducible. The combustion products (including soot) were quenched by nitrogen gas (7 lpm). The products were further diluted with air $(20 \mathrm{lpm})$ within the miniCAST system. Next, the SMPS measurements were performed at various $N_{2}$ flow rates through the probe. Subsequently, $10 \mathrm{lpm}$ was found to be enough to avoid soot aggregation in the sampling line, as inferred from the converged soot PSD, similar to $[32,44]$. For the miniCAST configuration, PPS measurement showed remarkable stability in the soot concentration with time, indicating no block245 age of the orifice. The dilution ratio $\left(N_{2} /\right.$ sample $)$ is determined to be $24: 1$ by comparing PPS measurements with the probe and directly without the probe. Recall, the additional air dilution $(\times 100)$ was used. Thus, the effective dilution ratio was $2400: 1$ by volume. The sample extraction set-up was identical (valve position, vacuum pump, etc.) as of the main campaign. Therefore, the dilution ratio deduced in miniCAST was used to calibrate the measurements performed in butane jet flames. Uncertainty in the dilution ratio is discussed subsequently in Sec. 3.3.

The sampling probe generally perturbs the flame through alteration of local temperature and upstream flow-field. Yet, a wealth of information can be extracted with fewer assumptions and lesser complexity than laser-based techniques. In laminar flames, perturbations are contained within a few $\mathrm{mm}$ upstream of the probe [29]. In the turbulent flame, upstream perturbations are expected to be lower due to larger flow momentum. Figure S4 in the Supplement shows flame photographs with the probe, suggesting low global perturbations.

260 Although, a discrepancy exists between LII and probe-derived soot concentration, especially at low Re (discussed in Sec. 3.3).

PPS (PPS-M 2000HC PEMS, Pegasor) provides the quasi-temporally resolved $(0.1 s)$ soot concentration. In the PPS technique, soot particles interact with ionized air. The exiting charged particles provide an estimate of escaping current, which is proportional to the soot concentration. A detailed working 
principle can be found in Ref. [35]. Once the escaping current $\left(I_{p p s}\right)$ is measured, soot mass concentration can be deduced as $C_{s}=K_{p p s} \cdot I_{p p s} / Q_{v}$, where $Q_{v}$ is the sample flow rate $(5 \mathrm{lpm})$ and $K_{p p s}$ is a constant $(1.05$, based on Diesel soot applications [45]). Next, the soot volume fraction can be deduced as $f_{v}-P P S=C_{s} / \rho_{\text {soot }}$, where $\rho_{\text {soot }}$ is a soot particle density which is assumed to be $1700 \mathrm{~kg} / \mathrm{m}^{3}$, based on a range of values reported in the literature (1500 [29] - $\left.1900[46] \mathrm{kg} / \mathrm{m}^{3}\right)$. The combined uncertainty in PPS is estimated to be $\pm 56 \%$. Individual error sources are discussed subsequently in Sec. 3.3.

The SMPS system (Classifier $3080+$ CPC 3010, TSI) was used to obtain the soot particle size distribution. The aerosol sample was supplied to the instrument at $1 \mathrm{lpm}$ flow rate, while the sheath flow rate was set to $10 \mathrm{lpm}$. SMPS counts the particle concentration by a sequential selection of classes of electrical mobility diameters over a specific range. Such scan duration is long ( 2 min for $7-290 \mathrm{~nm}$ ), and thus, SMPS is generally used in laminar flames $[26,28-30]$. Nevertheless, for the size range of interest (mode diameter 7 $30 \mathrm{~nm})$, the scan duration was short $(23 \mathrm{~s})$. The relative uncertainty in the particle size distribution shape is estimated to be $10 \%$ based on Ref. [32].

\section{Results and discussion}

\subsection{Flame temperature}

Temperature measurements were performed in low-sooting regions, where time-averaged $f_{v}$ was less than $0.1 \mathrm{ppm}$. Figure 4 shows the radiation corrected temperature profiles. In the case of turbulent flame (Fig. 4e), measurements for $y<60 \mathrm{~mm}$ were not performed since the flame was lifted. Recall, the present thermocouple could not measure temperature below $530 \mathrm{~K}$. To eliminate biased results, a dataset containing even a single instant of $T \leq 530 \mathrm{~K}$ was not retained. Therefore, the mean temperature is not available in some cases.

The peak flame temperature in Re 5000 flame at $y=10 \mathrm{~mm}$ in Fig. 4a measures $2261 \mathrm{~K}$, while $T_{a d}$ is $2267 \mathrm{~K}$. At $y=10 \mathrm{~mm}$, the soot concentration is negligible. Nevertheless, the temperature in non-premixed flames is expected 
to be lower than $T_{a d}$. Recall, at high temperature, $\pm 6 \%$ uncertainty (detailed in S1.4) exists. The actual peak flame temperature is likely to be lower. In Re 7200 flame, peak temperature (in Fig. 4c) at $y=10 \mathrm{~mm}$ is lower due to a lifted flame base (see Fig. 2b). The lift-off height for this flame measures $11 \mathrm{~mm}$ with a standard deviation $(\sigma)$ of $0.6 \mathrm{~mm}$ based on the OH-PLIF data [16]. At $y=$ $10 \mathrm{~mm}$, the flame leading edge spatially fluctuates. Therefore, the thermocouple is subjected to fluctuations between preheat and post-flame zones, which lowers the mean temperature. For a given $R e$, in general, the temperature decreases with increasing $y$. In Re 5000 flame (Fig. 4a), the radial peak temperature reduces by $\sim 150 \mathrm{~K}$ with increase in height from $y=10$ to $60 \mathrm{~mm}$. The soot radiation effect [47] alone cannot explain the observed drop in temperature since the measurements were restricted to low $f_{v}$ regions. Recall that the plotted temperatures in Fig. 4 are time-averaged. In addition to mean, we also deduce root mean square (RMS) values. This data is provided in the Supplementary material. Since the thermocouple response time is estimated to be $10 \mathrm{~ms}$, RMS values are indicative. Nonetheless, RMS can be compared on a relative basis across flames and measurement locations. The unsteadiness of the jet flames increases with height, as noted from increasing RMS values of temperature. Consequently, the thermocouple is subjected to spatial fluctuations between the peak (reaction zone) and moderate (preheat zone) temperature regions of the flame. Thus, the time-averaged temperature decreases with height.

With increasing $R e$, the peak flame temperature drops, accompanied by the increased profile widths. The flame stretch increases with $R e$ due to increased flame wrinkling (curvature) and flow strain, consequently lowering the instantaneous flame temperature. The mean temperature further reduces due to spatial fluctuations of the flame and associated time-averaging, as discussed earlier. Temperature profiles become broader due to increased flame-brush thickness with $R e$. In Fig. 4, the thermocouple enters from left $\left(r^{-}\right)$to right $\left(r^{+}\right)$. Temperature profiles are minutely asymmetric, which is attributed to the thermocouple perturbation towards $r^{+}$side in Fig. 4. Even this mild asymmetry could influence the temperature correlations with $\mathrm{OH}, \mathrm{PAH}$, and soot. Thus, 
only the left side $\left(r^{-}\right)$of the profile is retained for further analysis.

\subsection{Temperature correlations}

Temperature profiles are used to deduce correlations with soot concentration, soot-precursor $(\mathrm{PAH})$, and reaction zone $(\mathrm{OH})$ reported in the companion paper [16]. To visualize the spatial trends, the profiles are extracted from the timeaveraged planar data. Figure 5 shows PAH-LIF, $f_{v}$, and OH-LIF profiles at $y=$ $100 \mathrm{~mm}$, for Re 2100, 5000, and 7200 flames. Recall, temperature measurements in $R e 2100$ are not available. However, $\mathrm{OH}, \mathrm{PAH}$, and $f_{v}$ are available, and thus presented to enable comparison with other Re. For turbulent flame, the profiles

335 at $y=250 \mathrm{~mm}$ (where $f_{v}$ is appreciable) are plotted. A peak asymmetry is noted in $f_{v}$, which is attributed to possible beam steering and laser extinction along the path [37]. Therefore following Sun et al. [37] data only towards the laser-incident side is retained.

At Re 2100 (Fig. 5a), the radial order of the species from the jet axis is as 340 following: PAH, soot, and reaction zone. A minute OH-LIF signal near the jet core is attributed to interference from 1-2 ring PAH, as discussed in [16]. The radial order of species is the result of temperature and air/fuel mixing field. At a low oxygen concentration and a certain temperature range (700-1300 K [48]), PAH forms through pyrolysis of fuel. The smaller PAH gets converted to larger

345 PAH with increasing temperature. Subsequently, larger PAH coagulate and go through thermochemical processes to eventually form a nascent soot particle [49]. Next, soot particles grow through aggregation and surface reactions. Soot eventually gets oxidized in the vicinity of the flame, primarily through the $\mathrm{OH}$ route [50]. With an increase in $R e$, the PAH peak shifts from flame wing to the jet axis, while the annular structure of soot and reaction zone is preserved. The mass diffusion of the solid soot particles is negligible relative to the diffusion of gaseous species (PAH) [51]. In the turbulent flame (Fig. 5d), the time-averaged profiles become much broader than that of the laminar flame. The broadening of profiles is related to the spatial fluctuations induced by turbulent structures. 


\subsubsection{Temperature correlation with $\mathrm{OH}$}

The radial peak locations of OH-LIF and temperature are compared for different flames in Fig. 6 at several heights. The temperature profiles are much broader than that of the $\mathrm{OH}$, even in the laminar flame (Fig. 6a). The $\mathrm{OH}$ peak and temperature peak lie close to each other; however, the temperaturepeaks (and -profiles) are biased towards the fuel stream. In a non-premixed flame, combustion generally occurs at a stoichiometric surface, with products distributed on either side of the reaction zone. $\mathrm{OH}$ peaks in close vicinity of the stoichiometric surface but towards the fuel-lean side, as demonstrated by Donabar et al. [52] in a turbulent jet flame. Consequently, $\mathrm{OH}$ and temperature peaks do not overlap. In premixed flames, temperature peaks at a fuel-rich condition ( $\phi=1.05$ for $n$-butane). The appreciable shift of the temperature peak relative to $\mathrm{OH}$ in Fig. 6 suggests the occurrence of peak-temperature at even richer $\phi$. The observation deduced from Park et al. [24] indicates the occurrence of peak-temperature at $\phi \sim 1.2$ in a turbulent jet flame. In non-premixed flames, apart from chemical kinetics, convection and diffusion processes determine the peak-temperature $\phi[53]$. In the present flame, to identify $\phi$ corresponding to the peak-temperature, the mixture fraction data is needed.

\subsubsection{Temperature correlation with $P A H$}

The PAH-LIF profiles are also compared with the temperature in Fig. 7 for 375 different Re. In turbulent flame (Re 21500), no appreciable PAH is detected at lower height since the flame is lifted. In general, PAH concentration peaks in the fuel-rich low temperature zone. For quantitative comparison, temperature value at peak-PAH location is provided in Table 1 . In the attached flame (Re 5000) at the base, PAH peaks at a much lower temperature $(650 \mathrm{~K})$. Since reactant premixing is nearly absent in the attached flame, pyrolysis of fuel (that assist in $\mathrm{PAH}$ formation) may take place at a lower temperature. PAH peak shifts towards higher temperature with increasing height. This trend is likely associated with the increased diffusion of air with residence time (which is proportional to height). The presence of oxygen can shift the PAH formation to a 

and residence time.

\subsubsection{Temperature correlation with soot concentration}

The temperature-soot correlations are explored in a similar manner. For such correlations, generally, simultaneous measurements of temperature and delay between a change in local flow conditions and soot response, as evidenced from time-resolved measurements of Stöhr et al. [54]. Owing to longer soot reaction timescales (few ms), interpretation of instantaneous correlation is difficult in turbulent flames. The influence of soot response delay on time-averaged correlation is expected to be less significant than that of instantaneous correlation for a statistically stationary flow. To understand time-resolved soot-temperature correlation, high-speed simultaneous diagnostics is required where quantification is not trivial. Therefore, in this work, only time-averaged correlations are assessed.

Figure 8 shows the mean temperature and $f_{v}$ profiles in Re 7200 flame. Soot lies closer to the fuel-rich zone, away from the peak temperature location. The spatial trend between soot and temperature is similar to that reported in turbulent diluted ethylene flame by Park et al. [23]. The width of the temperature profile is larger than the $f_{v}$ profile. This observation is similar 
to that of $\mathrm{Gu}$ et al. [21]. In general, soot structures are highly localized due to a large Schmidt number of soot particles, which leads to a low soot mass diffusivity [55] relative to the thermal diffusivity of a gas. Consequently, the temperature profile width outgrows the soot profile width, as observed in Fig. 8. Similar to $R e 7200$ flame, the temperature and $f_{v}$ profiles are overlaid for other flames (but not shown for brevity).

Soot exists within a certain temperature range. To enable quantitative comparison, we deduce the mean gas temperature where time-averaged $f_{v}$ peaks. Figure 9 shows temperature profiles at select heights, along with the radial location of peak $f_{v}$ and corresponding temperature $\left(T_{f_{v}^{p k}}\right)$. In Re 5000 flame, $T_{f_{v}^{p k}}$ drops from 1400 to $1200 \mathrm{~K}$ with height in a $y$ range of 30 to $120 \mathrm{~mm}$. Note, the $T_{f_{v}^{p k}}$ trend is opposite of the temperature-PAH correlation where the temperature corresponding to peak-PAH increased with height. In Re 7200 flame, $T_{f_{v}^{p k}}$ decreases similarly from 1400 to $1300 \mathrm{~K}$ when $y$ increases from 60 to 120 $\mathrm{mm}$. The $y$ range for $R e 7200$ is different than the $R e 5000$ case to account for varying soot inception heights. The plot for Re 21500 flame is not shown since measurable $f_{v}$ and $T$ are available only at $y=120 \mathrm{~mm}$. In this turbulent flame, peak $f_{v}$ occurs around $1400 K$ (at $y=120 \mathrm{~mm}$ ). Despite the variation of turbulence level $(R e), T_{f_{v}^{p k}}$ at soot inception regions is almost identical with a value of $1400 \mathrm{~K}$. This optimum temperature is the result of a competition between soot formation and oxidation reactions. Soot formation is dominated by larger PAH, while oxidation is primarily influenced by $\mathrm{OH}[26]$. In the vicinity of flame, soot reaction with diffused $\mathrm{OH}$ can reduce the soot concentration. Consequently, $f_{v}$ peaks away from the high-temperature regions of the reaction zone.

440 The possible reasons for the decrease in $T_{f_{v}^{p k}}$ with height are discussed next. The peak flame temperature itself decreases with height due to the timeaveraging of unsteady flame, as discussed earlier. Apart from this, the nascent soot during inception may require higher temperatures to form. Conversely, at downstream locations, the soot growth is facilitated by surface reactions and ${ }_{445}$ transported PAH from upstream regions. The residence time also increases 
with height, which may decrease $T_{f_{v}^{p k}}$. With increasing height, OH may diffuse into the fuel-rich regions through diffusion and convective transports. As $\mathrm{OH}$ is the dominant soot oxidizer, $f_{v}^{p k}$ could shift to a lower temperature region with height.

The present findings are compared with the measurements in ethylene flames, since such data in turbulent $n$-butane flame is not yet reported. Note that the stoichiometric $T_{a d}$ of $n$-butane flame is $\sim 100 \mathrm{~K}$ lower than that of the ethylene. In turbulent ethylene lifted DLR jet flame $(R e=10000)$, the peak $f_{v}$ was reported [21] to exist in a $1550-1750 \mathrm{~K}$ range. This range is comparable to the $T_{f_{v}^{p k}} \approx 1600 \mathrm{~K}$ reported by Coppalle and Joyeux [17] in ethylene flame at $R e=11800$. In a different ethylene flame $(R e=20000$, pilot stabilized) $T_{f_{v}^{p k}} \approx 1400 \mathrm{~K}$ was reported [18]. Higher Re could lead to lower flame temperature due to increased flame-stretch. Additionally, measurements in [18] were path integrated over a larger region $(10 \mathrm{~mm})$, resulting in lower resolution.

${ }_{460}$ From a LIF-based temperature measurement in a diluted turbulent $(R e=8300)$ ethylene flame $[23,24]$, peak $f_{v}$ was shown to occur in a $1300-1500 \mathrm{~K}$ range in the soot inception region. This temperature range is lower compared to pure ethylene flames [17, 21], but lies closer to [18]. Park et al. [23] argued that with a diluted fuel, the flame temperature itself is lower, consequently resulting in 465 a low $T_{f_{v}^{p k}}$. In the present $n$-butane flames, $T_{f_{v}^{p k}}$ at the soot inception region $(1400 \mathrm{~K})$ is in agreement with a diluted ethylene flame of Park et al. [23, 24].

\subsection{Soot concentration from PPS}

The PPS-based soot concentrations are compared with that of LII from the companion work [16]. Note, the use of PPS was primarily intended to monitor the temporal evolution of the soot sample during an SMPS scan. Figure 10 shows the temporal evolution of soot volume fraction in aerosol sample extracted from $R e 7200$ flame at $y=250 \mathrm{~mm}$. The profile shows the initial spike as flame ignites. Subsequently, $f_{v}$ decreases due to the blockage of the probe orifice. The peak concentration associated with the flame transition is not retained. There 475 exists a distinct post-peak transition marked by a circle (in Fig. 10), which 
is assumed to be the quasi-steady soot concentration before any obstruction of the orifice. This procedure is adapted for all the measurements. The blockage of the probe orifice is lesser in the turbulent case due to lower $f_{v}$. The SMPS measurements are affected by the probe blockage over the scan time. Therefore, the SMPS data is corrected using PPS measurements, as detailed separately in Sec. S2.2 of the Supplement.

Soot concentrations obtained from PPS $\left(f_{v-P P S}\right)$ are compared with that of the LII $\left(f_{v-L I I}\right)$. Figure 11 shows the axial (centerline) mean profiles of $f_{v-L I I}$ along with $f_{v-P P S}$. The objective of this comparison is to assess the impact of probe perturbation on the flame. Overall, there is a qualitative agreement between $f_{v-P P S}$ and $f_{v-L I I}$. At Re 5000, $f_{v-P P S}$ appears to be shifted towards lower height relative to $f_{v-L I I}$. However, this discrepancy reduces with increasing $R e$. As Re increases, higher jet momentum results in lower probe perturbations. Additionally, at higher $R e$, the flame width increases, which reduces the PPS probe sensitivity to radial misalignment as well as to probe-induced radial fluctuations of $f_{v}$. These factors result in a better qualitative agreement between PPS and LII with increasing $R e$.

Although the qualitative trends are in agreement, absolute values of $f_{v-P P S}$ are much higher than $f_{v-L I I}$. The factor is 2.4 for $R e 5000$ and 7200 flames, whereas it measures 2.8 for Re 21500 flame. A discrepancy between in-situ (LII based) and ex-situ (SMPS based) $f_{v}$ values is reported recently [7]. The authors [7] argue that their LII measurements were biased towards larger soot particles (i.e., low LII sensitivity to smaller particles), and thus leading to lower LII-based $f_{v}$ relative to SMPS measurements. Note, $f_{v-L I I}$ in Fig. 11 is obtained from time-averaging, while $f_{v-P P S}$ is quasi time-resolved (averaged over $0.1 s)$. Additionally, spatial resolutions of LII and PPS differ. The in-plane magnification of LII is $\sim 0.2 \mathrm{~mm}$, while the out-of-plane resolution is expected to be $\sim 0.2 \mathrm{~mm}$ based on the laser-sheet thickness. The PPS resolution is five times coarser $(1 \mathrm{~mm})$ than LII. The larger probe volume and finer temporal resolution of PPS eliminate the soot intermittency effect as the soot is always present in the sample. Additionally, due to ex-situ nature of PPS, soot sam- 
ple may always be present in the sampling line. In contrast, significant soot intermittency is noted in spatially well-resolved LII measurements. Soot intermittency can lower $f_{v-L I I}$ when averaged unconditionally $[16,38,56]$. To isolate the effect of intermittency, the LII data can be conditionally averaged by considering samples only with the soot presence. The conditionally averaged peak axial $f_{v-L I I}$ measures nearly 3 times $(2.8,3.1$, and 3.5 for Re 5000, Re 7200, and Re 21500 respectively) as of the time-averaged one [16]. This factor is quite close to the ratio of time-averaged LII to PPS measurements shown in Fig. 11. The peak axial values of soot concentration from PPS and that of the conditionally averaged LII data are indeed in a reasonable $( \pm 15 \%)$ agreement.

Various sources of uncertainty in soot measurement are discussed next. Although assumed to be robust, uncertainty in LII can arise from the following sources. 1) Uncertainty in extinction-based LII calibration due to beam steering was verified to be insignificant. The mean $f_{v}$ value in a lifted ethylene flame $(R e=8700)$ with the present LII set-up was available to enable validation with a similar flame $(R e=10000)$ reported in $[2,21]$. The mean peak $f_{v}(0.56 \mathrm{ppm})$ was in close agreement with the value $(0.54 \mathrm{ppm})$ reported in $[2,21] .2)$ Uncertainty exists in the extinction coefficients $K_{e}$ used for LII calibration. $K_{e}$ varies with fuel and soot maturity (C-H composition) [57]. 3) The excitation laser beam steering in a turbulent flame can also affect the LII signal [37]. 4) Statistical uncertainty in the mean quantity arises due to fluctuations and a finite number of samples. The combined uncertainty (excluding $K_{e}$ ) from the above sources is estimated to be $\pm 19 \%$ [16].

The uncertainty in PPS can arise from the following sources. 1) There is inherent uncertainty in PPS-derived $f_{v}$ due to the transient nature originated from the probe blockage (recall Fig. 10). This uncertainty is estimated to be $\pm 15 \%$, based on the signal fluctuations. 2) The conversion of the PPS signal to the soot mass concentration involves soot particle size distribution assumption, which can lead to uncertainty up to $\pm 30 \%$ [58]. Furthermore, soot mass concentration is converted to $f_{v}$ through an assumed density, as indicated in 
Sec. 2.4. The soot density typically varies from $1500[29]$ to $1900[46] \mathrm{kg} / \mathrm{m}^{3}$ with soot maturity. Therefore, we use $1700 \mathrm{~kg} / \mathrm{m}^{3}$ soot density accompanied by ${ }_{540} \pm 15 \%$ uncertainty. 3) The uncertainty due to an error in probe positioning and upstream perturbations are estimated to be within $\pm 5 \mathrm{~mm}$, which translates to $f_{v}$ uncertainty of $\pm 15 \%$ based on LII fields [16]. 4) The absolute dilution ratio between the aerosol sample and $N_{2}$ is estimated in a separate calibration burner (recall Sec. 2.4) at a different flow velocity and temperature than the jet

${ }_{545}$ flames. The flow velocity can affect the pressure upstream of the probe, while temperature influences the quench gas $\left(N_{2}\right)$ expansion. Therefore, the dilution ratio could differ, which may be the major source of uncertainty. The dilution uncertainty could be high as $\pm 40 \%$ [29].

Total uncertainty from the above sources is estimated to be $\pm 56 \%$ through propagation. Further investigation and quantification are difficult to pursue with the available data owing to the turbulent flow. The PPS data is primarily used to correct the SMPS results for probe blockage. This correction can be accomplished even with a relative soot concentration since only the particle size distribution is intended from SMPS than the absolute concentration. The PPS technique has not yet been widely used in the fundamental soot research community. The agreement (within $\pm 15 \%$ ) between $f_{v-P P S}$ and conditionally averaged $f_{v-L I I}$ appears very promising, despite various uncertainty sources. This provides a base for technique-focused future works that could exploit PPS capabilities by addressing the aforementioned uncertainties. Unlike PPS, LII has been used widely (over a few decades) with a detailed understanding. Therefore, we retain only $f_{v-L I I}$ for the forthcoming analysis.

\subsection{Soot particle size}

\subsubsection{Soot particle size distribution}

The soot particle size distributions (PSDs) at different heights $(y)$ are shown in Fig. 12 for Re 5000 flame. Both raw and blockage-corrected PSDs are shown. The geometric mean diameter $\left(D_{g}\right)$ and standard deviation $\left(\sigma_{g}\right)$ are evaluated for both the corrected (C) and uncorrected (U) PSDs. Data within the entire 
range $(7-290 \mathrm{~nm})$ of SMPS scan duration $(120 \mathrm{~s})$ is considered to evaluate $D_{g}$ and $\sigma_{g}$.

In high-sooting regions $(y=310 \mathrm{~mm})$, large difference exists between $\sigma_{g C}$ and $\sigma_{g U}$ accompanied by much lower $D_{g C}$. This could be attributed to larger probe blockage with time. The data with orifice blockage $>95 \%$ at the end of SMPS scan duration $(120 s)$ is marked by *. A high blockage can lead to uncertainties in correction, especially for larger soot size $(>60 \mathrm{~nm})$. Therefore, the corrected data at $y=310$ and $370 \mathrm{~mm}$ should be interpreted with caution. As an alternative to $D_{g}$, a mode diameter (corresponding to the peak of PSD) can be evaluated. Note that the uncertainty in mode diameter $\left(D_{m}\right)$ due to blockage correction is not significant due to shorter SMPS scan duration over the range of interest $\left(23 \mathrm{~s}\right.$ until $30 \mathrm{~nm}$, and $75 \mathrm{~s}$ until $60 \mathrm{~nm}$ ). $D_{m}$ could be evaluated within $\pm 5 \%$ uncertainty from a given PSD.

Soot PSDs for Re 7200 flame are shown in Fig. 13. The orifice blockage correction in unsteady (intermittent) flame-tip region $(y=525$ and $580 \mathrm{~mm}$ ) and low-sooting region $(y=75 \mathrm{~mm})$ leads to increased fluctuations in PSD. On the other hand, the correction in a severe blockage case leads to high $\sigma_{g C}$ with lower $D_{g C}$ at $y=250,310$, and $370 \mathrm{~mm}$.

Similarly, PSDs for Re 21500 flame are shown in Fig. 14. At lower measurement stations $(y=75$ and $150 \mathrm{~mm}$ ), soot concentration (along the axis) is not appreciable. Thus, the lowest $y$ station is different than Re 5000 and 7200 flames. In turbulent flame, the probe orifice is the least blocked owing 590 close agreement. As the blockage is moderate, both $D_{g C}$ and $\sigma_{g C}$ are reliable throughout the measured axial locations.

All the PSDs (Figs. 12 to 14) exhibit a single mode within the present measurement range. This unimodality is in agreement with the PSD reported 595 in diluted ethylene jet flames [31]. However, LES investigation [8] in turbulent ethylene flame showed a bimodal PSD which is primarily prevalent downstream of the peak- $f_{v}$ location. The first mode [8] occurs at a much smaller diameter $(<$ $5 \mathrm{~nm}$ ), while the detection limit of the present system is $7 \mathrm{~nm}$. In turbulent 
toluene flame, Kruse et al. [22] also noted a bimodal distribution of $d_{p}$ in a soot oxidation region.

For a given $R e$, with increasing height $(y)$, soot particles are observed to be distributed over a wider size range, consistent with [21]. In inception regions (lower $y$ ), generally nascent soot particles exist without any aggregation. At a higher height, surface growth of primary soot particles takes place in addition to aggregation. This leads to a wider particle size distribution in downstream regions. Excluding the high-sooting and flame-tip regions, $\sigma_{g}$ in $R e 5000$ flame (Fig. 12) appears to increase from 1.5 to $1.6 \mathrm{~nm}$ with height. For Re 7200 flame, $\sigma_{g}$ varies over a larger range of 1.5 to $1.8 \mathrm{~nm}$ (Fig. 13). At $R e=21500$ (Fig. 14), $\sigma_{g}$ varies from $1.7 \mathrm{~nm}$ near the inception region to $1.9 \mathrm{~nm}$ near the ${ }_{610}$ peak- $f_{v}$ region. In turbulent flame, soot particles are distributed over a wider size range, even at soot inception regions. Although the soot size range increases with $R e$, the mode diameter in turbulent flame measures less than that of the lower Re flames. Turbulence could reduce the soot growth and aggregation owing to reduced residence time, soot precursor (PAH) concentration, and gas temperature.

\subsubsection{Soot particle size}

The axial evolution of soot mode diameter $\left(D_{m}\right)$ obtained from PSD is shown in Fig. 15 along with $f_{v-L I I}$. For all the cases in Fig. 15, the soot size increases with a height, similar to $f_{v}$, until both reach a peak. Beyond a certain distance, $f_{v}$ decreases, but $D_{m}$ shows a plateau until further downstream; afterward, $D_{m}$ decreases with height. The reduction in $D_{m}$ and $f_{v}$ is due to oxidation of soot (mainly by $\mathrm{OH}$ ) near the flame-tip region. Recall that the $f_{v-L I I}$ is timeaveraged, and thus, can be affected by soot intermittency. Since $D_{m}$ is the most probable value, it is less affected by soot intermittency. Conditionally averaged ${ }_{625} f_{v-L I I}$ reported in [16], confirms that the peak $f_{v}$ lies further downstream than that of the time-averaged $f_{v}$. This explains the difference in axial trends of $D_{m}$ and time-averaged $f_{v}$.

Since the soot particle size in turbulent $n$-butane flame is not yet been re- 
ported in the literature, we compare the present measurements with ethylenefueled turbulent flames and with a laminar $n$-butane flame. The $D_{m}$ range of the present jet flames is close to the one interpreted from PSD reported for a laminar premixed $n$-butane flame [30]. In turbulent non-premixed ethylene jet flame, Gu et al. [21] reported the primary soot diameter $\left(d_{p}\right)$ based on timeresolved LII. The mean $d_{p}$ followed a similar trend as of the mean $f_{v}$ with height.

${ }_{635}$ The most probable $d_{p}$ also showed an identical trend (and values) as of the mean $d_{p}$ with height. The peak in $d_{p}$ and $f_{v}$ occurred at the same location. A similar trend is noted in turbulent pre-vaporized toluene flame [22]. The present mode (most probable) diameter evolution shows a similar trend with $f_{v}$ as of [21, 22], within the measurement uncertainty.

640 Apart from qualitative trends, the soot particle size from ethylene flame [21] could be compared quantitatively with the present results while being aware of differences (in $R e$, fuel, soot size parameter). In ethylene flame [21], the most probable $d_{p}$ varies in $8-16 \mathrm{~nm}$ range. The mode diameter $D_{m}$ in the present turbulent $n$-butane flame (Re 21500) varies in $12-24 \mathrm{~nm}$ range, which

${ }_{645}$ is 1.5 times of the most probable $d_{p}$ with ethylene. Based on the PSD reported in laminar ethylene [29] and $n$-butane flames [30], we assume soot size in $n$ butane flames to be similar as of ethylene. Consequently, the $D_{m} / d_{p}$ ratio of 1.5 suggests a mild soot aggregation in the present flame. To conclude definitively, complementary $\left(d_{p}, D_{m}, R_{g y}, N_{p}\right.$, etc.) information is needed in an identical 650 flame.

Next, we compare the present $D_{m}$ trends with the mobility diameters reported by Chowdhury et al. [31]. The authors reported an axial variation of geometric mean diameter $\left(D_{g}\right)$ based on SMPS in diluted turbulent ethylene flame. Note that $D_{g}$ and $D_{m}$ need not be identical. $D_{g}$ in the present flame ${ }_{655}$ is listed on respective PSD provided in Sec. 3.4.1. $D_{g}$ measures consistently higher than $D_{m}$, typically 1.1 to 1.3 times as of $D_{m}$. The orifice blockage correction may lead to uncertainties in $D_{g}$ estimation for high sooting cases, as noted in Sec. 3.4.1. Recall, for $D_{g}$ evaluation, data over the entire scan range (120 $s$ duration) is needed. Conversely, $D_{m}$ evaluation requires data until peak 
probability, which corresponds to a smaller time delay (23 $s$ until $30 \mathrm{~nm}$ scan). Consequently, the correction uncertainties are minimal in $D_{m}$, and therefore, we chose to use $D_{m}$. The axial $D_{g}$ trend in [31] shows continuous growth until a certain downstream distance near the flame-tip. Beyond which measurements were not available. Therefore, the peak transition from a monotonic trend could not be identified. Additionally, the axial peak- $f_{v}$ location in this flame is not known to assess $f_{v}$ and soot size correlation. The $D_{g}$ variation range in [31] is rather small $(3-6 \mathrm{~nm})$ relative to the mean $d_{p}(5-16 \mathrm{~nm})$ reported in pure ethylene flame [21]. The smaller soot size in [31] is likely due to the dilution $\left(65 \% N_{2}\right)$ of ethylene. Decrease in $d_{p}$ with $N_{2}$ dilution has also been reported 670 by Sun et al. [59].

In the present undiluted $n$-butane flames, the soot size $\left(D_{m}\right)$ ranges from 12 to $28 \mathrm{~nm}$, as observed from Fig. 15. Soot particles much smaller $(2-4 \mathrm{~nm})$ than the present range have been reported [27] in low sooting laminar $n$-butane nucleation flames. The present SMPS set-up is unable to resolve such a small size which may occur in soot nucleation regions. In the attached flame (Fig. 15a), $D_{m}$ measures $20 \mathrm{~nm}$ near the inception region, whereas in lifted flames (Figs. $15 \mathrm{~b}$ and $15 \mathrm{c}$ ) corresponding $D_{m}$ is $\sim 12 \mathrm{~nm}$. In lifted flames, partial premixing is anticipated. The soot size appears to be highly sensitive to the local fuel concentration. Partial premixing can reduce the fuel pyrolysis, which in turn decreases the concentration of PAH needed for the soot growth. Nevertheless, the smaller $D_{m}$ in lifted flame (Re 7200, Fig. 15b) grows to a peak value of $28 \mathrm{~nm}$, which is the same as of Re 5000 attached flame. At Re 5000 and 7200, $D_{m}$ rises sharply after the inception, similar to the $f_{v}$ trend. In turbulent flame (Fig. $15 \mathrm{c}$ ), $D_{m}$ rise trend is almost identical as of $f_{v}$. Peak $D_{m}$ measures $24 \mathrm{~nm}$, 685 which is slightly lower than $R e 5000$ flame $(28 \mathrm{~nm})$. Increased $R e$ reduces the soot size marginally. With an increase in $R e$, the residence time and temperature decrease, while air/fuel mixing enhances, which combinedly leads to lower $D_{m}$.

The effect of lift-off originated partial premixing is investigated by Grader et al. [60] through LES. The impact of partial premixing is mainly relevant in the soot inception and growth regions. In the downstream locations (between 
soot growth and oxidation regions), combustion was shown to occur primarily in the non-premixed regime. This may be the reason for the substantial rise in $D_{m}$ with height in lifted flames despite the upstream partial premixing.

\section{Conclusions}

The present paper reports the temperature and soot particle size in $n$-butane jet flames. The effect of exit Re on correlations between temperature and various parameters, namely $f_{v}$, soot-precursor $(\mathrm{PAH})$, and reaction zone $(\mathrm{OH})$, are investigated. The soot particle size distribution was obtained at different $R e$. Additionally, soot concentration was measured using the ex-situ PPS device.

Time-averaged flame temperature decreases with $R e$ due to increased flamestretch and averaging in an unsteady flame. For a given $R e$, the mean flame temperature decreases with height. The temperature and $\mathrm{OH}$ peaks are nearly aligned; however, the temperature peak is biased towards the fuel-rich side of the flame. Soot-precursor $(\mathrm{PAH})$ peaks at a much lower temperature $(650 \mathrm{~K})$ in the attached flame (Re 5000) than in the lifted flame (850 K in Re 7200). In turbulent lifted flame (Re 21500), peak-PAH occurs at a higher temperature (940 K). Partial premixing of air/fuel in the lifted flames can significantly increase the temperature required for $\mathrm{PAH}$ formation. The mean temperature at peak- $f_{v}$ location $\left(T_{f_{v}^{p k}}\right)$ was measured in low-sooting regions. $T_{f_{v}^{p k}}$ decreases from 1400 to $1200 \mathrm{~K}$ with height in $R e 5000$ flame. At downstream locations, the soot growth may be facilitated by surface reactions and transported soot-precursors from upstream regions, and thus resulting in the lower $T_{f_{v}^{p k}}$. Despite the variation in turbulence level $(R e=5000-21500)$, peak $f_{v}$ at soot inception region occurs at a nearly constant value around $1400 \mathrm{~K}$. The soot-temperature correlation is governed by the competition between soot formation through larger PAH and oxidation by $\mathrm{OH}$ near the reaction zone. These competing processes dictate the value of $T_{f_{v}^{p k}}$ which is found to be less sensitive to $R e$ in the soot inception region. To obtain further insights into the soot-temperature correlation, time-resolved (i.e., high-speed) simultaneous measurements will be beneficial 

timescales.

A quasi-instantaneous (averaged over $0.1 s) f_{v-P P S}$ deduced from the ex-situ PPS technique is in qualitative agreement with the in-situ time-averaged $f_{v-L I I}$. However, $f_{v-P P S}$ measures 2.4 to 2.8 times of $f_{v-L I I}$. This difference is primarily attributed to the time-averaging of $f_{v-L I I}$ in an intermittent field. If the soot intermittency is accounted for by conditional averaging of $f_{v-L I I}$, a reasonable quantitative agreement (within $\pm 15 \%$ ) between $f_{v-L I I}$ and $f_{v-P P S}$ is noted.

The mode diameter $\left(D_{m}\right)$ of soot particle peaks around the same axial region 730 as the peak $f_{v} . D_{m}$ at a moderate $R e$ (5000 or 7200) varies between $12-28 \mathrm{~nm}$, whereas at $\operatorname{Re} 21500$ peak- $D_{m}$ decreases marginally to $24 \mathrm{~nm}$. Turbulence can reduce the soot growth and aggregation owing to a reduced residence time, soot precursor concentration, and temperature. Although $D_{m}$ decreases with $R e$, soot particles are distributed over a wider size range, possibly due to reduced of the primary diameter reported in a turbulent ethylene flame [21], suggesting a moderate soot aggregation in the present flame.

In this manner, the present work examined the influence of $R e$ on temperaturesoot correlations and soot particle size. The application of the PPS device is demonstrated for the first time to measure the in-flame soot concentration. Additionally, soot particle size in a turbulent $n$-butane flame is provided using SMPS. The data provided insights into the effect of upstream partial premixing and turbulence on soot size. The comprehensive database containing a wide range of parameters and boundary conditions, from the present and companion ${ }_{745}$ (Part 1) [16] papers, can contribute towards the development and validation of turbulence and soot-chemistry models for fuels of practical relevance. 


\section{Acknowledgments}

The project (ASMAPE) was funded by the French National Research Agency (ANR) under contract no. ANR-13-TDMO-0002. Dr. I.A. Mulla acknowledges

750 awarded by the European Commission under H2020-EU.1.3.2 scheme. The assistance of Mr. F. Lefebvre in thermocouple fabrication and of Mr. B. Quevreux in component fabrication is gratefully acknowledged. The authors thank Dr. G. Lefebvre for his aid in the installation of particle analyzers. The authors also 755 acknowledge the support of Dr. G. Godard and Mrs. C. Gobin in laser installations. 
Table 1: Temperature at peak PAH radial location at different $y(\mathrm{~mm})$.

\begin{tabular}{cccc}
\hline \multirow{2}{*}{$R e$} & \multicolumn{2}{c}{$T(K)$ at peak PAH } \\
\cline { 2 - 4 } & $y=20$ & $y=60$ & $y=120$ \\
\hline 5000 & 650 & 730 & 865 \\
7200 & 850 & 875 & 885 \\
21500 & - & - & 940 \\
\hline
\end{tabular}


(a)

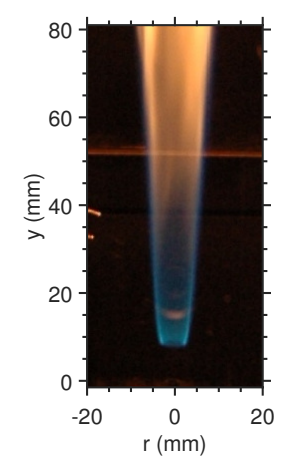

(b)

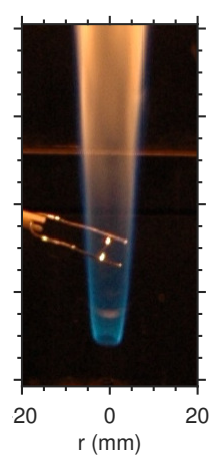

Figure 1: Re 7200 flame: (a) without thermocouple, and (b) with thermocouple at $y=30 \mathrm{~mm}$.

(a)

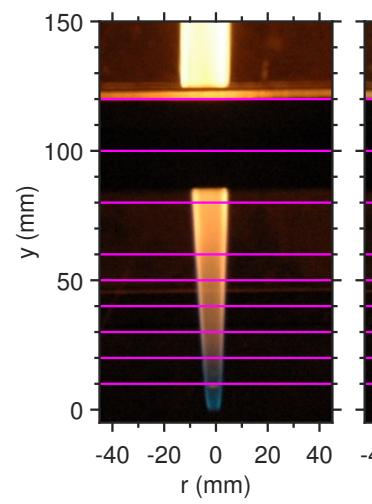

(b)

(c)

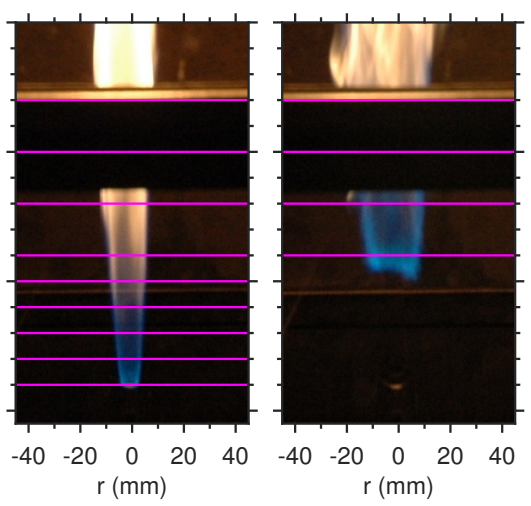

Figure 2: Flame photographs: (a) Re 5000, (b) Re 7200, and (c) Re 21500. Temperature measurement stations are marked by magenta lines. 


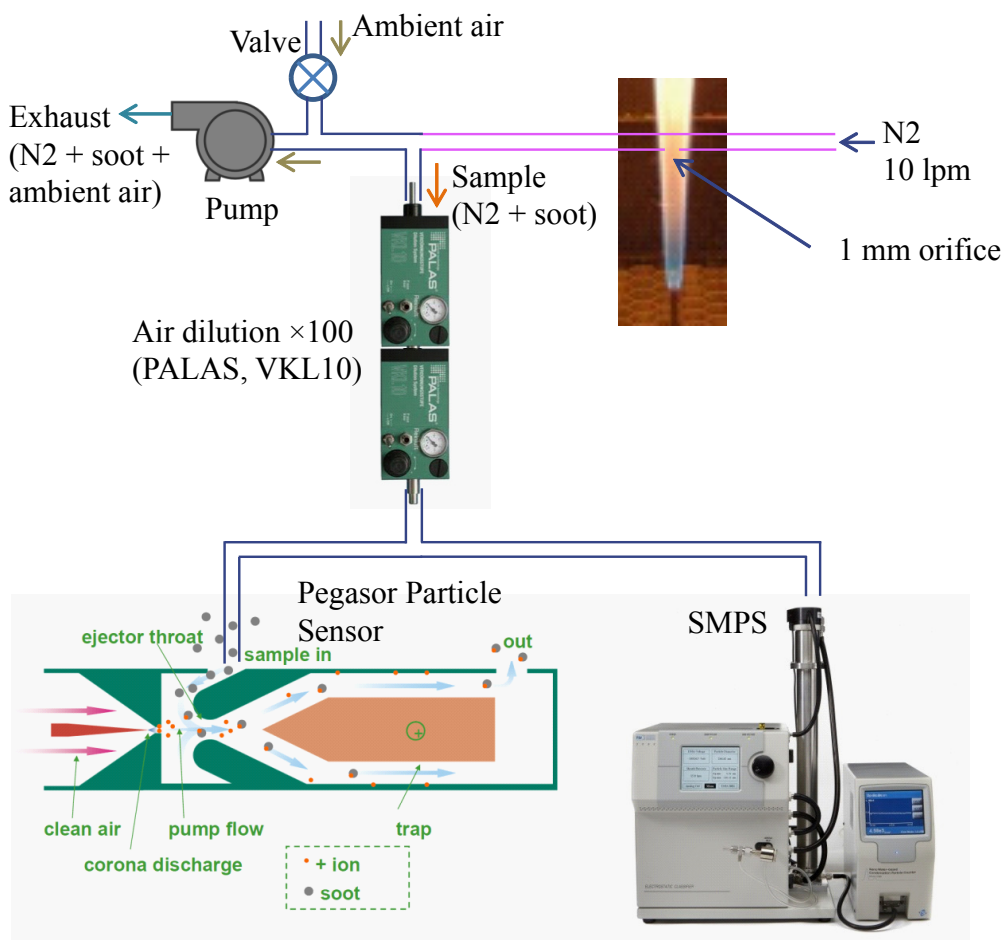

Figure 3: Probe sampling set-up for SMPS and PPS measurements. 
(a)

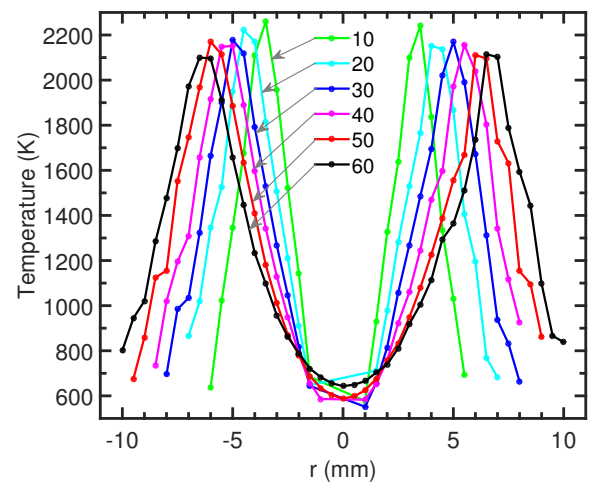

(c)

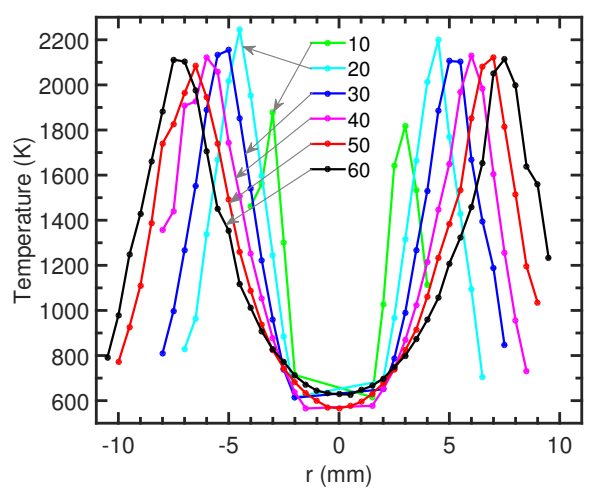

(b)

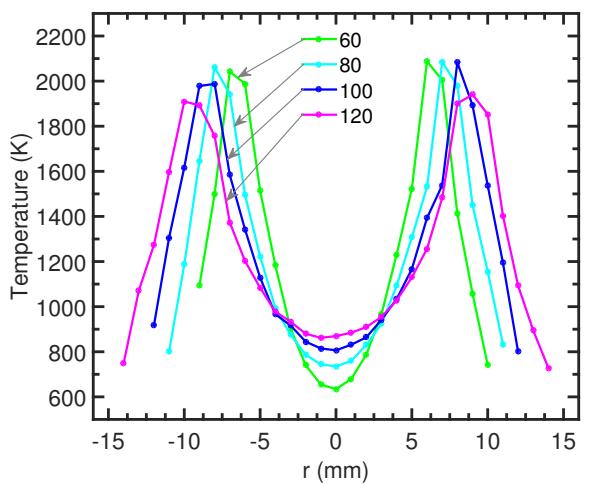

(d)

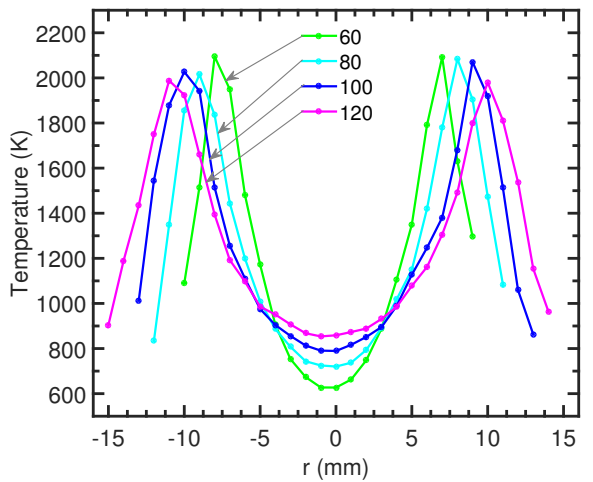

(e)

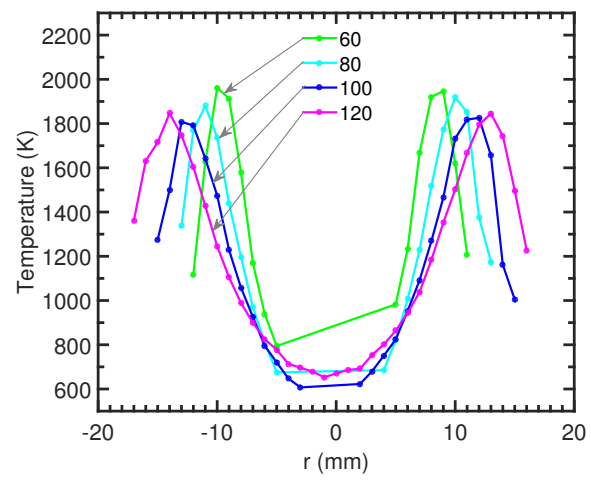

Figure 4: Mean temperature radial profiles: (a, b) Re 5000, (c, d) $\operatorname{Re} 7200$, and (e) $\operatorname{Re} 21500$. The legend shows axial $y$ stations (in $m m$ ) as marked in Fig. 2. 
(a)

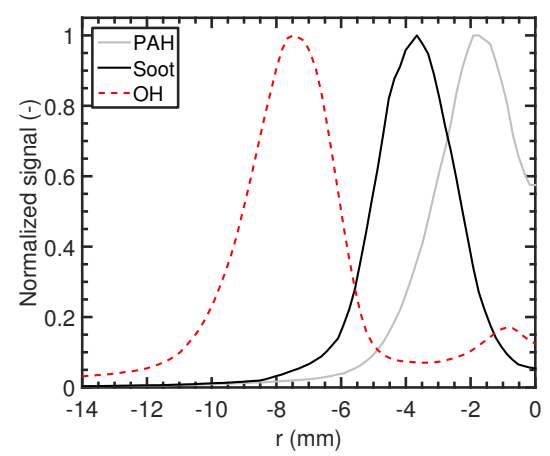

(c)

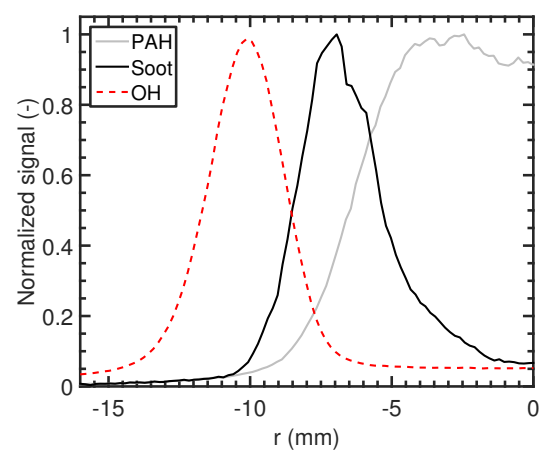

(b)

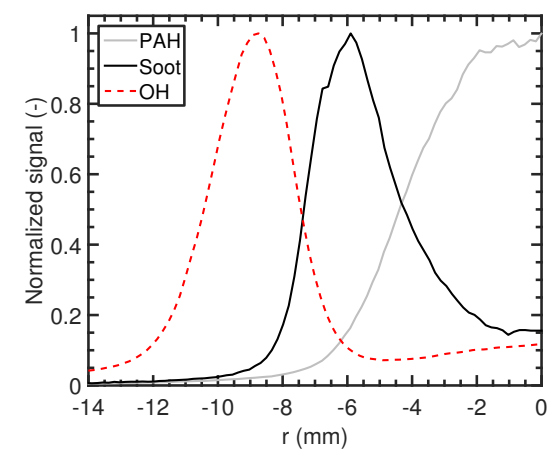

(d)

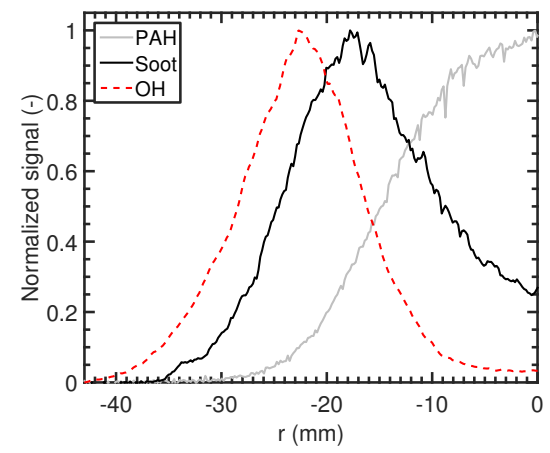

Figure 5: PAH-LIF, Soot concentration, OH-LIF mean radial profiles: (a) Re 2100 at $y=$ $100 \mathrm{~mm}$, (b) $\operatorname{Re} 5000$ at $y=100 \mathrm{~mm}$, (c) $\operatorname{Re} 7200$ at $y=100 \mathrm{~mm}$, and (d) $\operatorname{Re} 21500$ at $y=250 \mathrm{~mm}$. The profiles are extracted from the data reported in [16] 
(a)

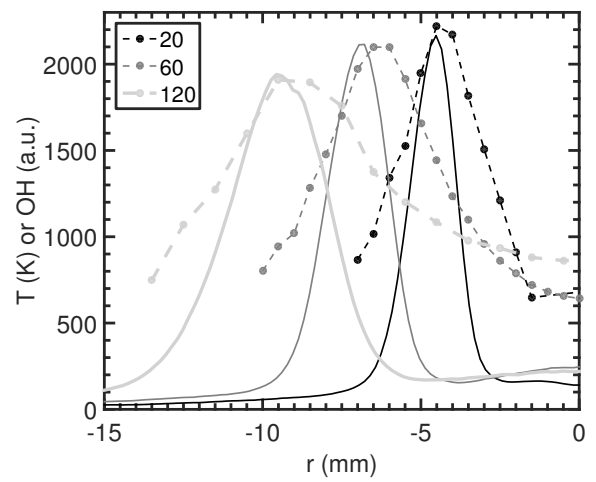

(b)

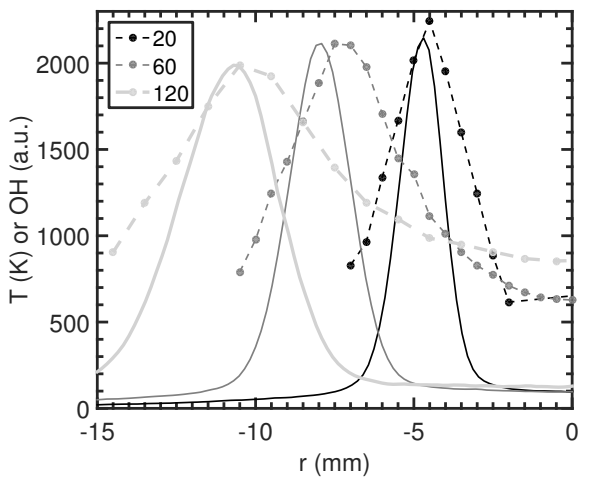

(c)

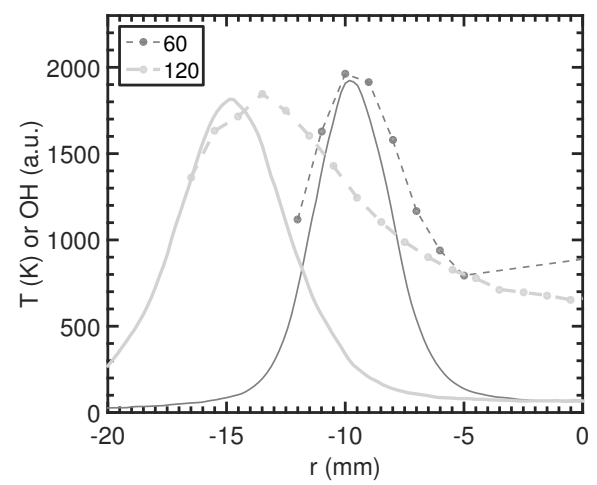

Figure 6: Temperature (dashed line) and OH-LIF (solid line) mean radial profiles: (a) Re 5000, (b) Re 7200, and (c) Re 21500. The legend shows axial $y$ location (in $\mathrm{mm}$ ). 
(a)

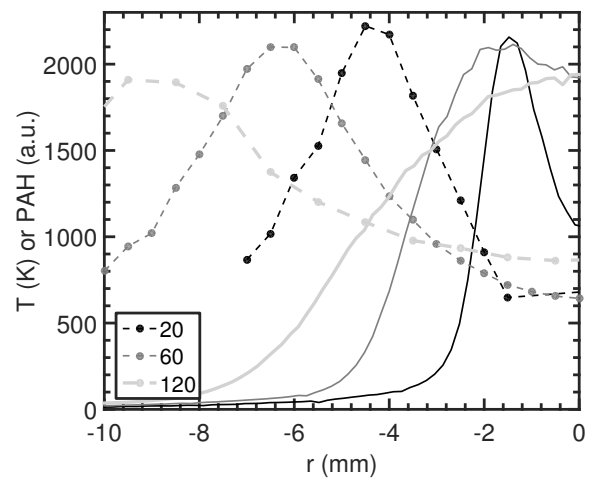

(c) (b)

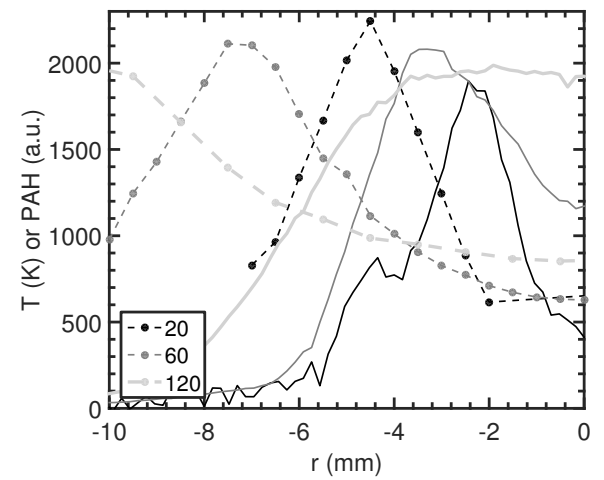

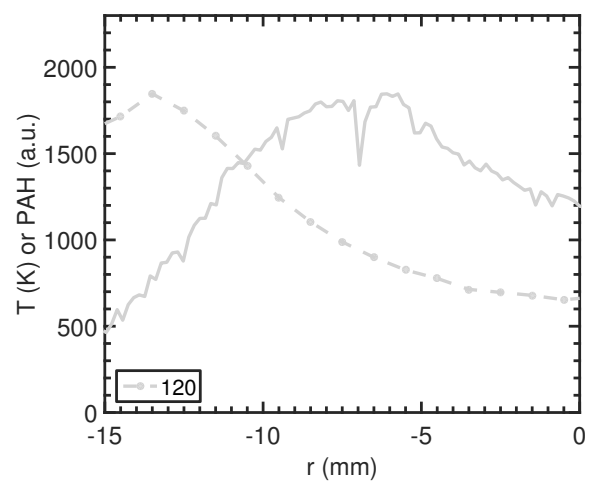

Figure 7: Temperature (dashed line) and PAH-LIF (solid line) mean radial profiles: (a) Re 5000, (b) Re 7200, and (c) Re 21500. The legend shows axial y location (in $\mathrm{mm}$ ). 
(a)

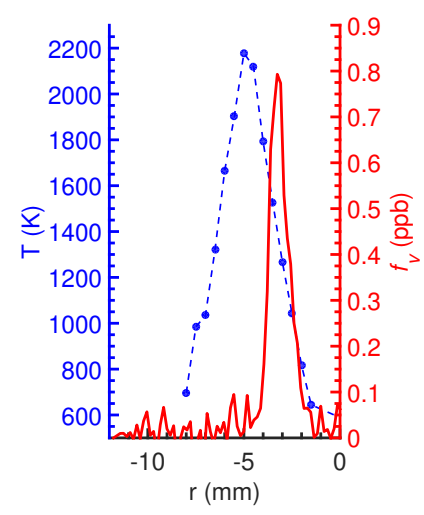

(b)

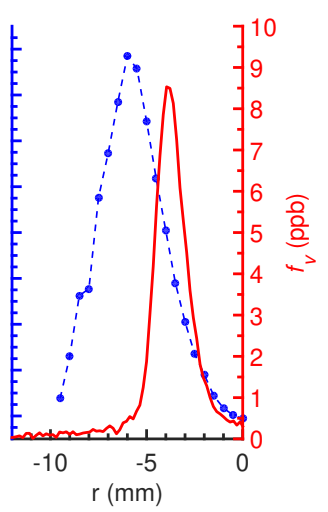

(c)

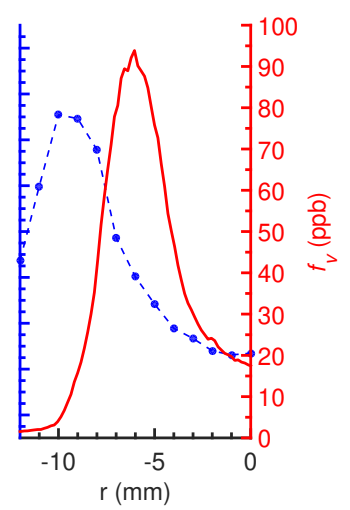

Figure 8: Temperature (dashed line) and $f_{v}$ (solid line) profiles in $R e 7200$ flame at: (a) $y=30 \mathrm{~mm}$, (b) $y=50 \mathrm{~mm}$, and (c) $y=120 \mathrm{~mm}$.

(a)

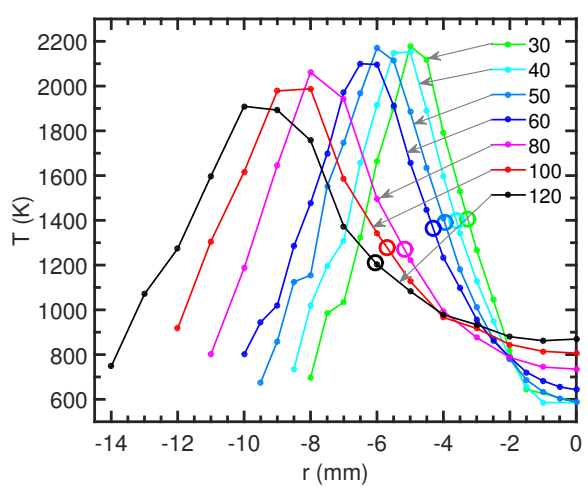

(b)

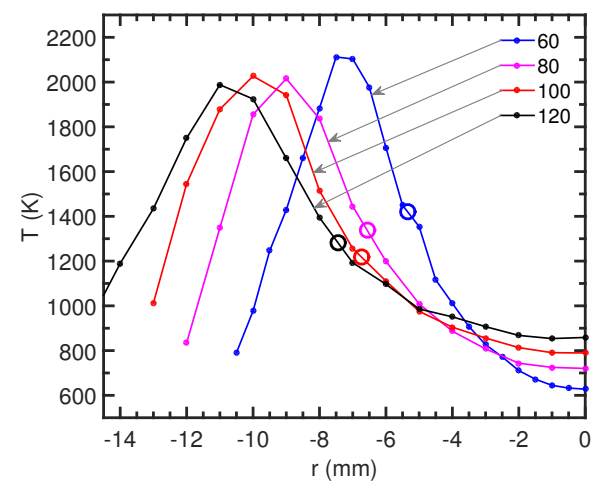

Figure 9: Temperature profiles where open circles mark the temperature at peak soot concentration location for: (a) Re 5000, (b) Re 7200. Axial $y$ locations (in $m m$ ) are indicated in the legend. 


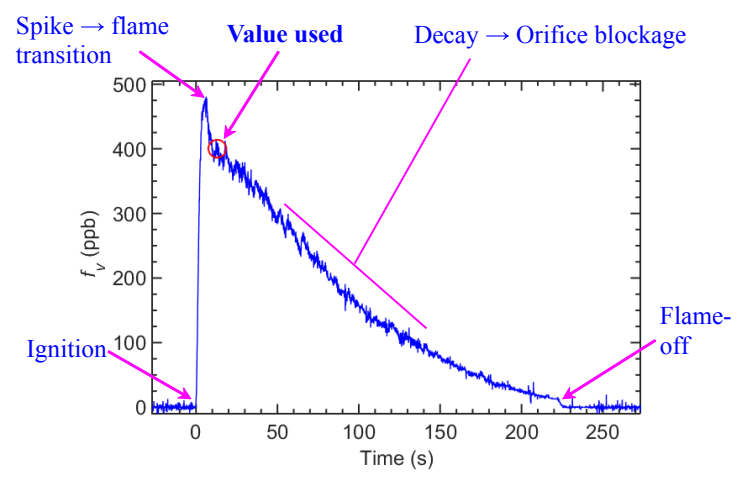

Figure 10: PPS trace in Re 7200 flame at $r=0 \mathrm{~mm}, y=250 \mathrm{~mm}$.

(a)

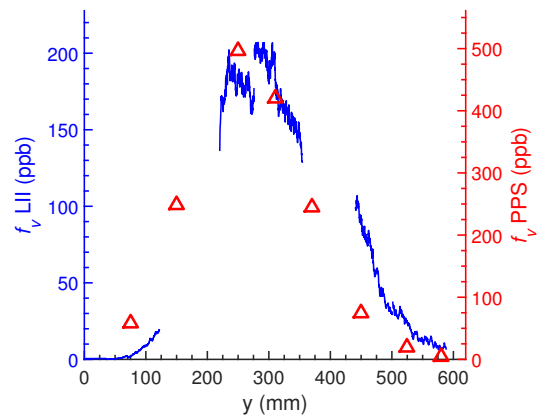

(c) (b)

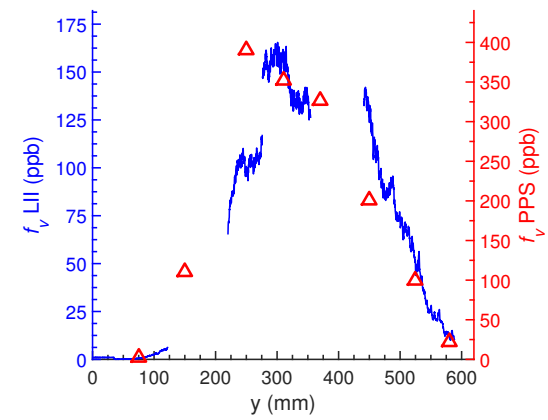

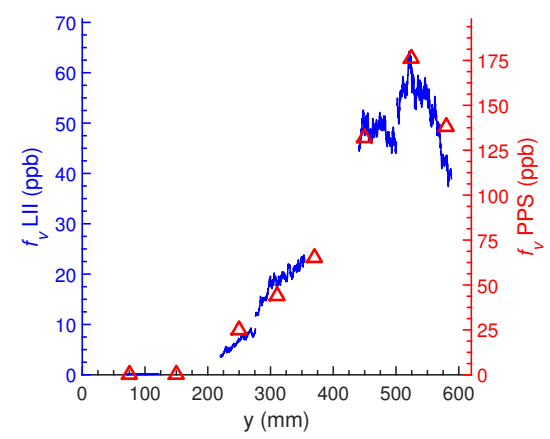

Figure 11: Axial $f_{v}$ profiles from LII (line) and PPS (symbols): (a) Re 5000, (b) Re 7200, and (c) Re 21500 . 


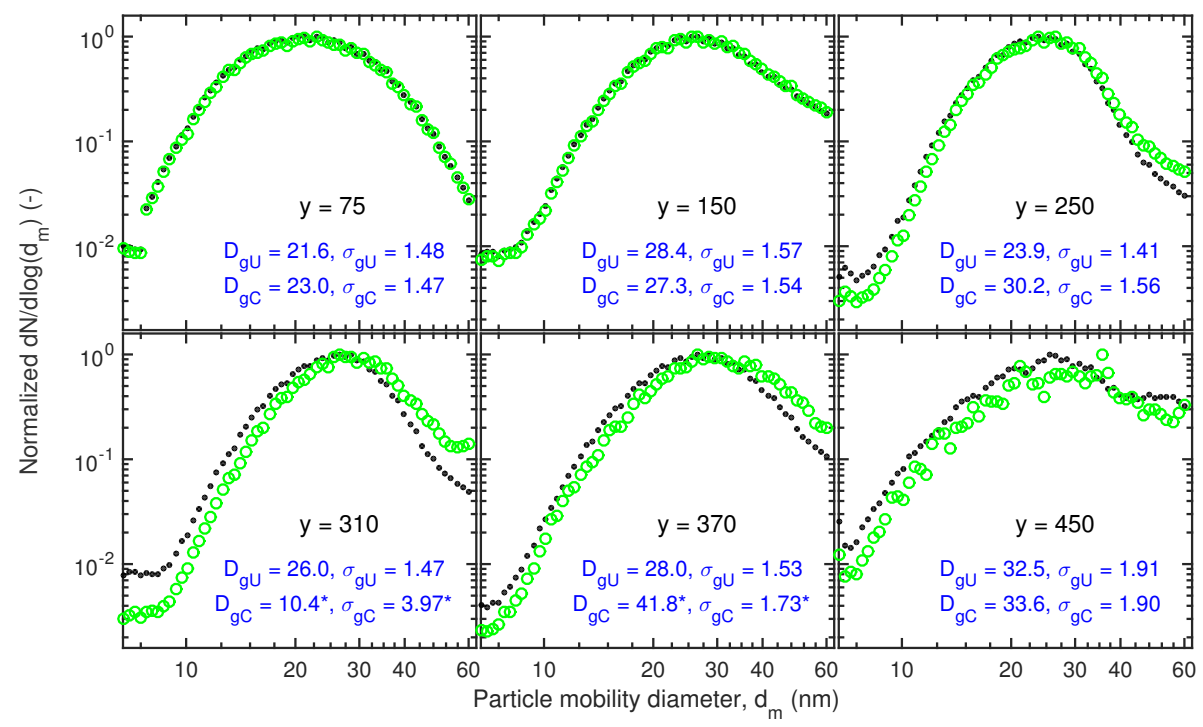

Figure 12: Soot PSDs at different heights $(y$ in $\mathrm{mm}$ ) along the burner axis in Re 5000 flame. $D_{g}$ and $\sigma_{g}$ are specified in $n m$. (•) without blockage correction, (॰) with correction. 


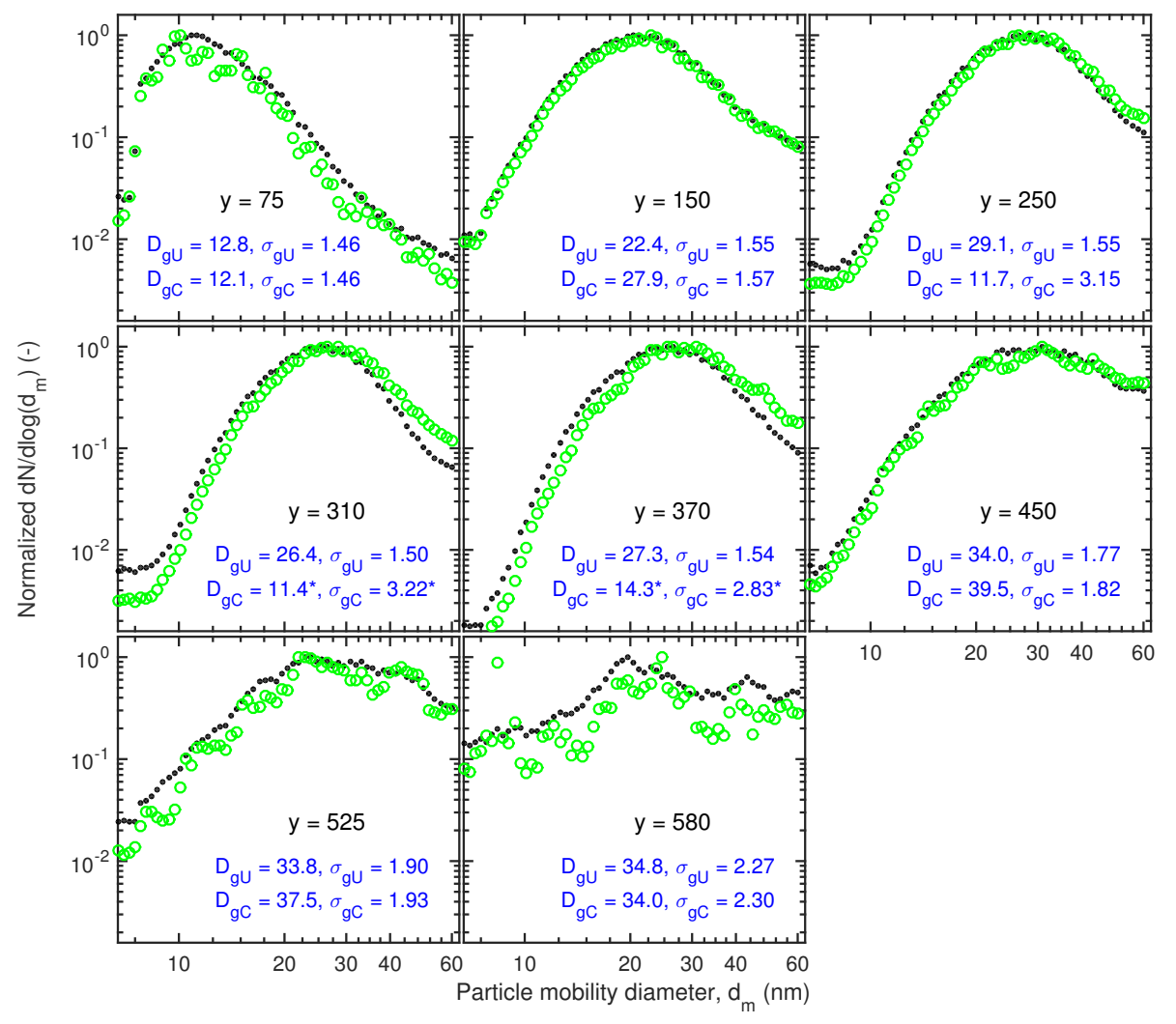

Figure 13: Soot PSDs at different heights along the burner axis in $R e 7200$ flame. (•) without blockage correction, (॰) with correction. 


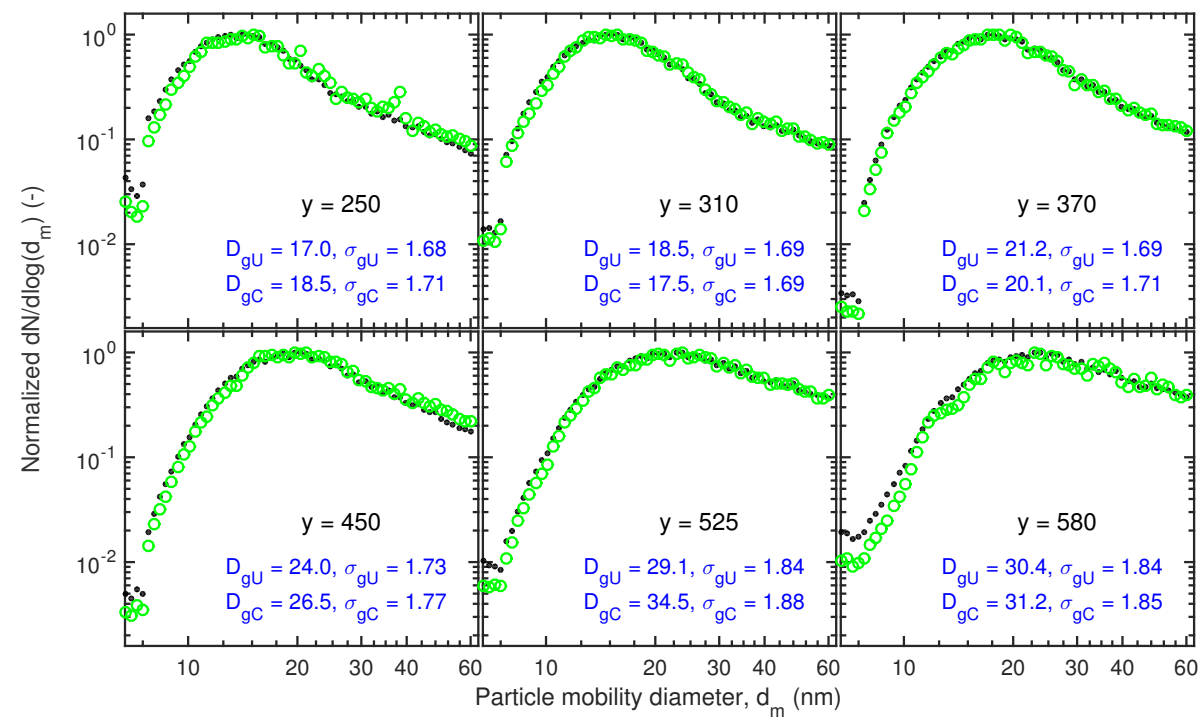

Figure 14: Soot particle size distribution at different heights along the burner axis in $R e 21500$ flame. (•) without blockage correction, (॰) with correction. 
(a)

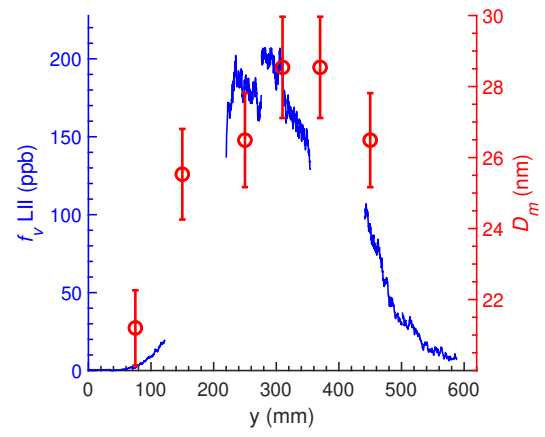

(c) (b)

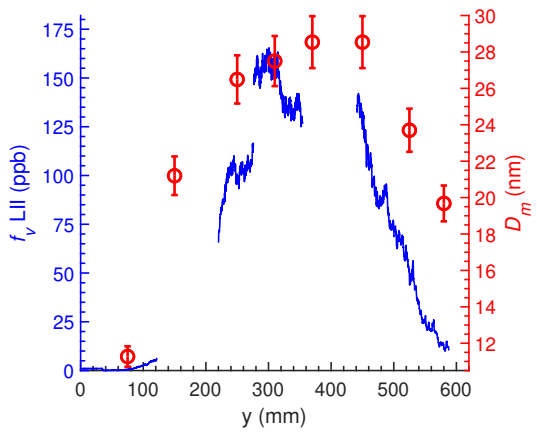

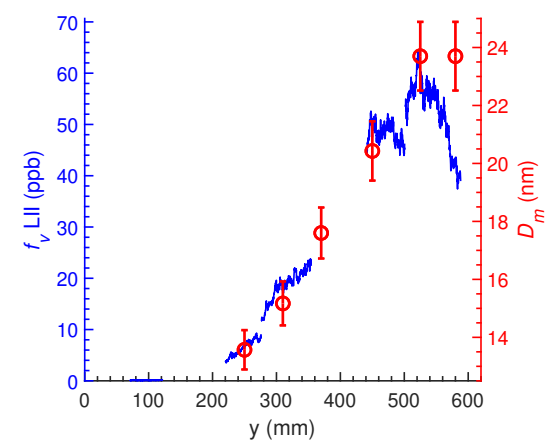

Figure 15: Soot mode diameter $D_{m}$ (symbols) and $f_{v}$-LII (line) variation along the axis: (a) Re 5000, (b) Re 7200, and (c) Re 21500. 


\section{References}

[1] C. R. Shaddix, J. Zhang, R. W. Schefer, J. Doom, J. C. Oefelein, S. Kook, L. M. Pickett, H. Wang, Understanding and predicting soot generation in turbulent non-premixed jet flames, Sand2010-7178, Sandia Report.

[2] M. Köhler, K. P. Geigle, W. Meier, B. M. Crosland, et al., Sooting turbulent jet flame: characterization and quantitative soot measurements, Appl. Phys. B 104 (2) (2011) 409-425. doi:10.1007/s00340-011-4373-y.

[3] M. Köhler, K.-P. Geigle, T. Blacha, P. Gerlinger, W. Meier, Experimental characterization and numerical simulation of a sooting lifted turbulent jet diffusion flame, Combust. Flame 159 (8) (2012) 2620-2635. doi:10.1016/ j.combustflame.2012.01.015.

[4] K. P. Geigle, W. O'Loughlin, R. Hadef, W. Meier, Visualization of soot inception in turbulent pressurized flames by simultaneous measurement of laser-induced fluorescence of polycyclic aromatic hydrocarbons and laserinduced incandescence, and correlation to $\mathrm{OH}$ distributions, Appl. Phys. B 119 (4) (2015) 717-730. doi:10.1007/s00340-015-6075-3.

[5] K. P. Geigle, R. Hadef, M. Stöhr, W. Meier, Flow field characterization of pressurized sooting swirl flames and relation to soot distributions, Proc. Combust. Inst. 36 (3) (2017) 3917-3924. doi:10.1016/j .proci.2016.09. 024.

[6] I. E. Helou, A. W. Skiba, E. Mastorakos, Experimental investigation of soot production and oxidation in a lab-scale rich-quench-lean (RQL) burner, Flow Turbul. Combust. 106 (4) (2020) 1019-1041. doi:10.1007/ s10494-020-00113-5.

[7] G. D. Falco, I. E. Helou, P. M. de Oliveira, M. Sirignano, R. Yuan, A. D'Anna, E. Mastorakos, Soot particle size distribution measurements in a turbulent ethylene swirl flame, Proc. Combust. Inst. 38 (2) (2021) 2691-2699. doi:10.1016/j.proci.2020.06.212. 
[8] P. Rodrigues, B. Franzelli, R. Vicquelin, O. Gicquel, N. Darabiha, Coupling an LES approach and a soot sectional model for the study of sooting turbulent non-premixed flames, Combust. Flame 190 (2018) 477-499. doi:10.1016/j.combustflame.2017.12.009.

[9] H. Koo, V. Raman, M. E. Mueller, K.-P. Geigle, LES of a sooting flame in a pressurized swirl combustor, in: 54th AIAA Aerospace Sciences Meeting, American Institute of Aeronautics and Astronautics, 2016. doi:10.2514/ 6.2016-2123.

[10] A. Wick, F. Priesack, H. Pitsch, Large-eddy simulation and detailed modeling of soot evolution in a model aero engine combustor, in: Volume 4A: Combustion, Fuels and Emissions, ASME, 2017. doi:10.1115/ gt2017-63293.

[11] B. Franzelli, A. Vié, N. Darabiha, A three-equation model for the prediction of soot emissions in LES of gas turbines, Proc. Combust. Inst. 37 (4) (2019) 5411-5419. doi:10.1016/j.proci.2018.05.061.

[12] S. Gkantonas, M. Sirignano, A. Giusti, A. D'Anna, E. Mastorakos, Comprehensive soot particle size distribution modelling of a model rich-quench-lean burner, Fuel 270 (2020) 117483. doi:10.1016/j.fuel.2020.117483.

[13] N. M. Marinov, W. J. Pitz, C. K. Westbrook, A. M. Vincitore, M. J. Castaldi, S. M. Senkan, C. F. Melius, Aromatic and polycyclic aromatic hydrocarbon formation in a laminar premixed n-butane flame, Combust. Flame 114 (1-2) (1998) 192-213. doi:10.1016/s0010-2180 (97) 00275-7.

[14] W. J. Pitz, C. K. Westbrook, Chemical kinetics of the high pressure oxidation of n-butane and its relation to engine knock, Combust. Flame 63 (1-2) (1986) 113-133. doi:10.1016/0010-2180 (86) 90115-x.

[15] Y. Huang, C. Sung, J. Eng, Dilution limits of n-butane/air mixtures under conditions relevant to HCCI combustion, Combust. Flame 136 (4) (2004) 457-466. doi:10.1016/j. combustflame.2003 .10.011. 
[16] I. Mulla, B. Lecordier, P. Desgroux, A. Cessou, Comprehensive characterization of sooting butane jet flames, Part 1: soot, soot-precursor, and reaction zone, Combust. Flame CNF-D-18-00805R1 (2021) Accepted.

[17] A. Coppalle, D. Joyeux, Temperature and soot volume fraction in turbulent diffusion flames: Measurements of mean and fluctuating values, Combust. Flame 96 (3) (1994) 275-285. doi:10.1016/0010-2180(94)90014-0.

[18] C. R. Shaddix, J. Zhang, Joint temperature-volume fraction statistics of soot in turbulent non-premixed jet flames, in: 8th U.S. National Combustion Meeting, 2013, p. paper 2E11.

[19] Q. N. Chan, P. R. Medwell, P. A. Kalt, Z. T. Alwahabi, et al., Simultaneous imaging of temperature and soot volume fraction, Proc. Combust. Inst. 33 (1) (2011) 791-798. doi:10.1016/j.proci.2010.06.031.

[20] S. Mahmoud, G. Nathan, P. Medwell, B. Dally, Z. Alwahabi, Simultaneous planar measurements of temperature and soot volume fraction in a turbulent non-premixed jet flame, Proc. Combust. Inst. 35 (2) (2015) 1931-1938. doi:10.1016/j.proci.2014.06.122.

[21] D. Gu, Z. Sun, B. B. Dally, P. R. Medwell, et al., Simultaneous measurements of gas temperature, soot volume fraction and primary particle diameter in a sooting lifted turbulent ethylene/air non-premixed flame, Combust. Flame 179 (2017) 33-50. doi:10.1016/j. combustflame.2017.01.017.

[22] S. Kruse, J. Ye, Z. Sun, A. Attili, et al., Experimental investigation of soot evolution in a turbulent non-premixed prevaporized toluene flame, Proc. Combust. Inst. 37 (1) (2019) 849-857. doi:10.1016/j.proci.2018.05. 075.

[23] O. Park, R. A. Burns, O. R. Buxton, N. T. Clemens, Mixture fraction, soot volume fraction, and velocity imaging in the soot-inception region of a turbulent non-premixed jet flame, Proc. Combust. Inst. 36 (1) (2017) 899-907. doi:10.1016/j.proci.2016.08.048. 
[24] O. Park, R. A. Burns, N. T. Clemens, Relationship between soot and scalar dissipation rate in the soot-inception region of turbulent non-premixed jet flames, Proc. Combust. Inst. 37 (1) (2019) 1057-1064. doi:10.1016/j . proci.2018.06.174.

[31] S. Chowdhury, W. R. Boyette, W. L. Roberts, Time-averaged probability density functions of soot nanoparticles along the centerline of a piloted 
turbulent diffusion flame using a scanning mobility particle sizer, J. Aerosol Sci. 106 (2017) 56-67. doi:10.1016/j.jaerosci.2016.10.012.

[32] W. Boyette, S. Chowdhury, W. Roberts, Soot particle size distribution functions in a turbulent non-premixed ethylene-nitrogen flame, Flow Turbul. Combust. 98 (4) (2017) 1173-1186. doi:10.1007/s10494-017-9802-5.

[33] J. Jang, Y.-J. Lee, O. Kwon, M. Lee, J. Kim, The effect of engine oil on particulate matter, emissions and fuel economy in gasoline and diesel vehicle, in: SAE Technical Paper Series, SAE International, 2014. doi: $10.4271 / 2014-01-2837$.

[34] L. Tarabet, K. Loubar, M. Lounici, K. Khiari, et al., Experimental investigation of DI diesel engine operating with eucalyptus biodiesel/natural gas under dual fuel mode, Fuel 133 (2014) 129-138. doi:10.1016/j.fuel. 2014.05 .008$.

[35] S. Amanatidis, M. M. Maricq, L. Ntziachristos, Z. Samaras, Measuring number, mass, and size of exhaust particles with diffusion chargers: The dual pegasor particle sensor, J. Aerosol Sci. 92 (2016) 1-15. doi:10.1016/ j.jaerosci.2015.10.005.

[36] R. C. Deo, J. Mi, G. J. Nathan, The influence of reynolds number on a plane jet, Phys. Fluids 20 (7) (2008) 075108. doi:10.1063/1.2959171.

[37] Z. W. Sun, Z. T. Alwahabi, D. H. Gu, S. M. Mahmoud, et al., Planar laser-induced incandescence of turbulent sooting flames: the influence of beam steering and signal trapping, Appl. Phys. B 119 (4) (2015) 731-743. doi:10.1007/s00340-015-6080-6.

[38] S.-Y. Lee, S. R. Turns, R. J. Santoro, Measurements of soot, OH, and $\mathrm{PAH}$ concentrations in turbulent ethylene/air jet flames, Combust. Flame 156 (12) (2009) 2264-2275. doi:10.1016/j.combustflame.2009.09.005.

[39] V. Narayanaswamy, N. Clemens, Simultaneous LII and PIV measurements in the soot formation region of turbulent non-premixed jet flames, Proc. 
Combust. Inst. 34 (1) (2013) 1455-1463. doi:10.1016/j .proci.2012.06. 018.

[40] S. Mahmoud, G. Nathan, Z. Alwahabi, Z. Sun, P. Medwell, B. Dally, The

[46] F. Liu, K. Daun, D. Snelling, G. Smallwood, Heat conduction from a spherical nano-particle: status of modeling heat conduction in laser-induced 
incandescence, Appl. Phys. B 83 (3) (2006) 355-382. doi:10.1007/ s00340-006-2194-1.

[47] F. Liu, H. Guo, G. J. Smallwood, O. L. Gülder, Effects of gas and soot radiation on soot formation in a coflow laminar ethylene diffusion flame, J. Quant. Spectrosc. Radiat. Transfer 73 (2-5) (2002) 409-421. doi:10. $1016 / \mathrm{s} 0022-4073(01) 00205-9$.

[48] H. Nakamura, R. Tanimoto, T. Tezuka, S. Hasegawa, K. Maruta, Soot formation characteristics and PAH formation process in a micro flow reactor with a controlled temperature profile, Combust. Flame 161 (2) (2014) 582591. doi:10.1016/j.combustflame.2013.09.004.

${ }_{935}$ [49] A. D'Anna, M. Commodo, M. Sirignano, P. Minutolo, R. Pagliara, Particle formation in opposed-flow diffusion flames of ethylene: An experimental and numerical study, Proc. Combust. Inst. 32 (1) (2009) 793-801. doi: $10.1016 / j$.proci. 2008.06 .200$.

[50] H. Guo, P. M. Anderson, P. B. Sunderland, Optimized rate expressions for soot oxidation by $\mathrm{OH}$ and O2, Fuel 172 (2016) 248-252. doi:10.1016/j . fuel.2016.01.030.

[51] A. Kronenburg, R. Bilger, J. Kent, Modeling soot formation in turbulent methane-air jet diffusion flames, Combust. Flame 121 (1-2) (2000) 24-40. doi:10.1016/s0010-2180(99)00146-7.

${ }_{945}$ [52] J. M. Donbar, J. F. Driscoll, C. D. Carter, Reaction zone structure in turbulent nonpremixed jet flames - from CH-OH PLIF images, Combust. Flame 122 (1-2) (2000) 1-19. doi:10.1016/s0010-2180(00)00098-5.

[53] S. Turns, An introduction to combustion: Concepts and Applications, 3rd Ed., McGraw-Hill, 2012.

[54] M. Stöhr, K. Geigle, R. Hadef, I. Boxx, C. Carter, M. Grader, P. Gerlinger, Time-resolved study of transient soot formation in an aero-engine model 
combustor at elevated pressure, Proc. Combust. Inst. 37 (4) (2019) 54215428. doi:10.1016/j.proci.2018.05.122.

[55] F. Bisetti, G. Blanquart, M. E. Mueller, H. Pitsch, On the formation and early evolution of soot in turbulent nonpremixed flames, Combust. Flame 159 (1) (2012) 317-335. doi:10.1016/j.combustflame.2011.05.021.

[56] B. M. Crosland, K. A. Thomson, M. R. Johnson, Simultaneous instantaneous measurements of soot volume fraction, primary particle diameter, and aggregate size in turbulent buoyant diffusion flames, Proc. Combust. Inst. 35 (2) (2015) 1851-1859. doi:10.1016/j.proci.2014.06.003.

[57] T. Williams, C. Shaddix, K. Jensen, J. Suo-Anttila, Measurement of the dimensionless extinction coefficient of soot within laminar diffusion flames, Int. J. Heat Mass Transfer 50 (7-8) (2007) 1616-1630. doi:10.1016/j. ijheatmasstransfer.2006.08.024.

[58] L. Ntziachristos, P. Fragkiadoulakis, Z. Samaras, K. Janka, J. Tikkanen, Exhaust particle sensor for OBD application, in: SAE Technical Paper Series, SAE International, 2011. doi:10.4271/2011-01-0626.

[59] Z. Sun, B. Dally, G. Nathan, Z. Alwahabi, Effects of hydrogen and nitrogen on soot volume fraction, primary particle diameter and temperature in 970 laminar ethylene/air diffusion flames, Combust. Flame 175 (2017) 270-282. doi:10.1016/j. combustflame.2016.08.031.

[60] M. Grader, C. Eberle, P. Gerlinger, Large-eddy simulation and analysis of a sooting lifted turbulent jet flame, Combust. Flame 215 (2020) 458-470. doi:10.1016/j.combustflame.2020.01.042. 